\title{
Converting non-neutralizing SARS-CoV-2 antibodies targeting conserved epitopes into broad-spectrum inhibitors through receptor blockade
}

\author{
Payton A.-B. Weidenbachera, ${ }^{a, b}$ Eric Waltaric, Izumi de los Rios Kobara ${ }^{d}$, Benjamin N. \\ Bella,e, John E. Pak ${ }^{\mathrm{c}}$, Peter S. Kimª, ${ }^{\mathrm{a}, \mathrm{f}}$
}

\section{Abstract}

All but one of the authorized monoclonal antibody-based treatments for SARS-CoV-2 are largely ineffective against Omicron, highlighting the critical need for biologics capable of overcoming SARS-CoV-2 evolution. These mostly ineffective therapeutic antibodies target epitopes that are not highly conserved. Here we describe broad-spectrum SARS-CoV-2 inhibitors developed by tethering the SARS-CoV-2 receptor, angiotensin-converting enzyme 2 (ACE2), to antibodies that are known to be non-neutralizing, but which target highly conserved epitopes in the viral spike

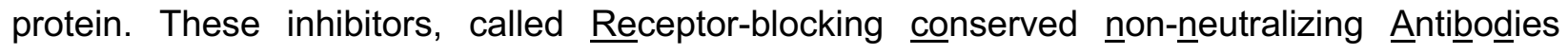
(ReconnAbs), potently neutralize all SARS-CoV-2 variants of concern (VOC), including Omicron. Neutralization potency is dependent on both the binding and inhibitory ReconnAb components as activity is lost when the linker joining the two is severed. In addition, a bifunctional ReconnAb, made by linking ACE2 to a bispecific antibody targeting two non-overlapping conserved epitopes, defined here, shows sub-nanomolar neutralizing activity against all VOCs, including Omicron. Given their conserved targets and modular nature, ReconnAbs have the potential to act as broadspectrum therapeutics against SARS-CoV-2 and other emerging pandemic diseases.

\footnotetext{
a Stanford ChEM-H, Stanford University, Stanford, CA 94305

b Department of Chemistry, Stanford University, Stanford, CA 94305

c Chan Zuckerberg Biohub, San Francisco, CA 94158

d Stanford Immunology Program, Stanford University School of Medicine, Stanford, CA 94305

e Department of Molecular and Cellular Physiology, Stanford University School of Medicine, Stanford, California 94305

f Department of Biochemistry, School of Medicine, Stanford University, Stanford, CA 94305
} 


\section{Introduction}

The emergence of the Omicron variant has rendered six of the seven ${ }^{1-9}$ clinically available monoclonal antibodies (mAbs) essentially ineffective against SARS-CoV-2 - only sotrovimab retains robust neutralizing activity against Omicron $^{10,11}$. These clinical mAbs all target the receptor binding-domain $(\mathrm{RBD})^{1-9}$ of the spike protein and were selected for their neutralizing potency against Wuhan-Hu-1 SARS-CoV-2. The six mAbs besides sotrovimab target non-conserved (variable) regions of the $\mathrm{RBD}^{4,12-18}$ and prevent interaction with its receptor, human angiotensin converting enzyme 2 (ACE2) $)^{16,19-21}$. Sotrovimab, a derivative of the mAb $S 309^{22-25}$, was initially isolated from a SARS-CoV-1 survivor, so its epitope in the RBD is more highly conserved, ${ }^{9}$ although in vitro escape mutations have been identified ${ }^{14}$.

The spike protein is large ( $450 \mathrm{kDa}$ as a trimer), and contains extensive regions that are extremely highly conserved (Fig. $1 \mathrm{~A})^{26-29}$. Some residues on the spike that are distant from the RBD have near-perfect sequence identity within related coronaviruses (Fig. 1B) ${ }^{30,31}$. Presumably, these regions are highly conserved because they are required for viral activity (e.g., membrane fusion $)^{32}$. While the spike protein of Omicron has a much larger mutational profile than that of previous variants of concern (VOCs) ${ }^{33}$, with 36 total mutations, 15 being in the RBD ${ }^{11,34,35}$, the highly-conserved epitopes remain largely unaltered (Fig. 1). ${ }^{11,34,35}$

In other viral spike proteins, for instance influenza hemagglutinin ${ }^{36-41}$, highly conserved epitopes outside of the receptor-binding region are targets of potent broadly neutralizing antibodies (bnAbs). However, despite the heightened interest sparked by the global pandemic, the search for bnAbs against betacoronaviruses has been largely disappointing. While one conserved helical epitope at the base of the spike protein has been shown to elicit rare mAbs with relatively broad neutralizing activity, their potency is often weaker than RBD-directed neutralizing $\mathrm{Abs}^{42-45}$. Further, neutralizing N-terminal domain (NTD) ${ }^{46,47}$ antibodies have been identified, but their epitopes are not highly conserved. 
bioRxiv preprint doi: https://doi.org/10.1101/2022.01.24.477625; this version posted January 25, 2022. The copyright holder for this preprint (which was not certified by peer review) is the author/funder, who has granted bioRxiv a license to display the preprint in perpetuity. It is made available under aCC-BY-NC-ND 4.0 International license.

Indeed, available evidence suggests that conserved regions outside the RBD generally elicit non-neutralizing $\mathrm{mAbs}^{43,48-54}$. We hypothesized that we could generate potent, broadspectrum inhibitors by modifying existing non-neutralizing antibodies which target highly conserved epitopes on the spike protein to also contain a receptor-blocking component. Due to the conservation of their epitopes, such inhibitors would potentially be broadly neutralizing.

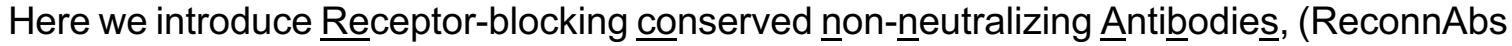
- pronounced recon-abs), a novel class of therapeutic proteins in which non-neutralizing

\section{Figure 1}
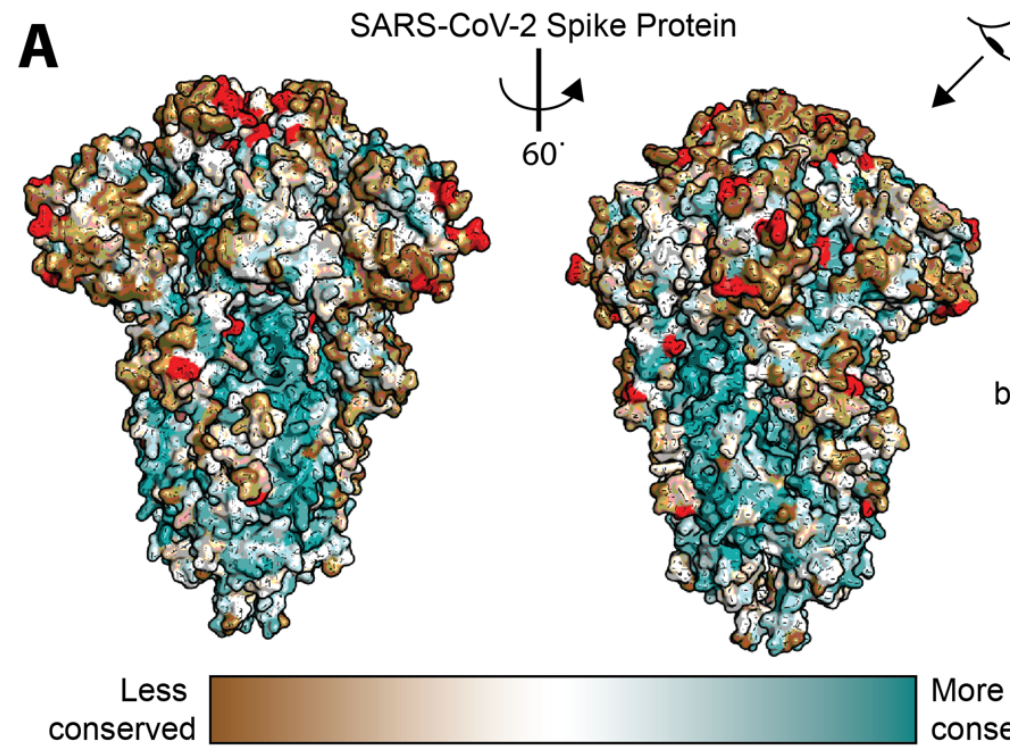

More conserved

Omicron mutations
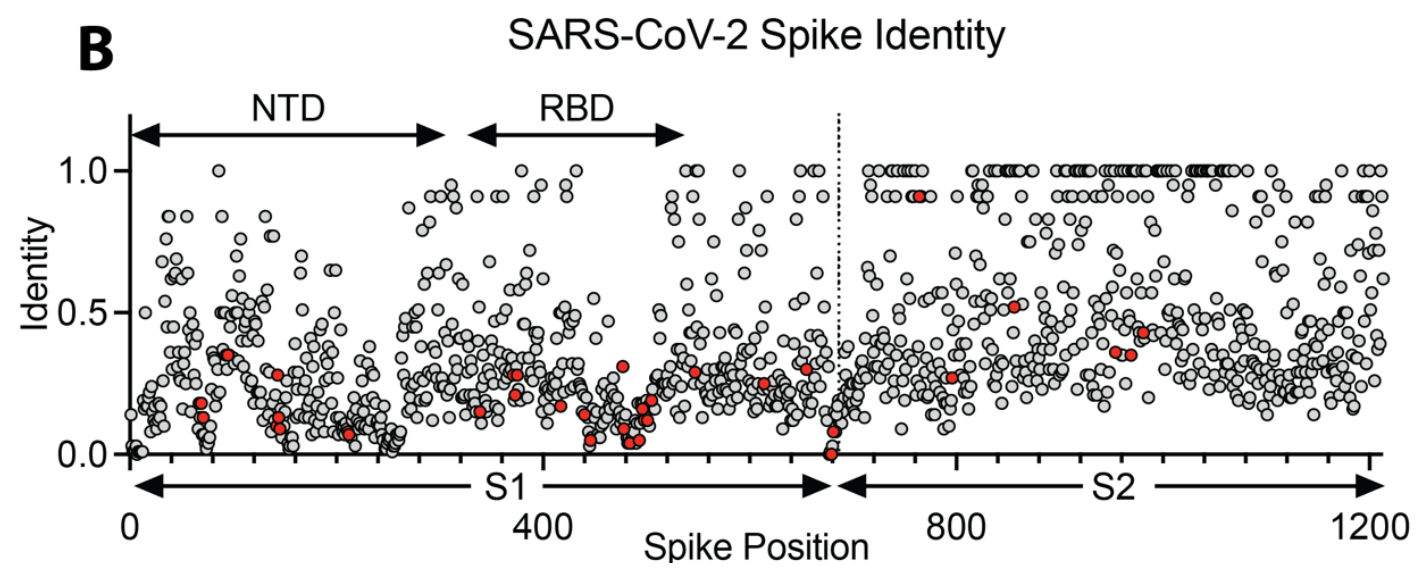

Figure 1 - Conservation of the SARS-CoV-2 spike protein. (A) Sequence conservation from 44 related spike proteins overlaid on the SARS-CoV-2 spike protein structure (left) and the SARS-CoV-2 RBD (right residues 319-541) (PDB ID: 6VXX) identifies a highly conserved patch in S2. (B) Sequence identity for all residues in the SARS-CoV-2 spike protein compared to a set of 44 related coronavirus spike proteins shows higher conservation in the S2 relative to $\mathrm{S} 1$. A value of 1.0 means perfect identity across all compared coronavirus proteins. RBD and NTD domains of SARS-CoV-2 spike are labeled on top, S1 and S2 domains are labeled on bottom. 
antibodies that target highly conserved, non-RBD epitopes, are tethered to the ACE2 receptor, which otherwise has low intrinsic affinity and neutralizing potency. The cross-reactive, nonneutralizing antibodies were identified in a two-step process. First, we analyzed the phylogenetic trees of a collection of SARS-CoV-2 antibodies and eliminated those that are likely to bind the RBD. Then, similar to the development of sotrovimab, ${ }^{9}$ we determined which of these non-RBD antibodies bound to the SARS-CoV-1 spike protein. We predict that ReconnAbs will have both increased potency, due to the increase in effective concentration of each component ${ }^{55}$, as has been shown previously for non-neutralizing antibody fusions ${ }^{56}$, but more importantly, increased broad-spectrum activity by targeting highly conserved, non-RBD epitopes on spike. ReconnAbs show neutralizing activity against all SARS-CoV-2 VOCs tested, including Omicron. Further, a bispecific ReconnAb containing two non-neutralizing antibodies with non-overlapping epitopes fused to ACE2 confers sub-nanomolar neutralization against all VOCs tested. Our findings reveal the benefit of repurposing highly cross-reactive, non-neutralizing antibodies to create a new class of broad-spectrum anti-viral agents.

\section{Results}

To first profile the landscape of non-neutralizing antibodies, we produced a library of SARS-CoV-2 spike-binding antibodies not directed against the RBD. To ensure library diversity, we first curated the publicly available SARS-CoV-2 antibody repository CoV-AbDab ${ }^{46,57-60}$ for sequences specifically from COVID-19 convalescent donors that bound to the spike protein outside of the RBD. From this limited set of 696 antibody sequences, we generated phylogenetic trees for both the antibody heavy chain (HC) and light chain (LC). We constructed phylogenies using amino acid sequences of full-length $\mathrm{V}$-genes and the CDR3 region. We also included one 
allele of each germline $\mathrm{V}$-gene into the phylogenies to provide context for germline diversity of the antibody dataset.

We compiled non-RBD-binding antibodies, focusing specifically on the clustering of the non-RBD-binding sequences within the HC phylogenetic tree (Fig. 2A). We identified distinct clusters on the heavy/light chain phylogenetic trees and chose 48 diverse sequences spread throughout the tree (Fig. 2A and Supplementary Fig. 1). These included at least one antibody sequence from all clusters containing at least four or more non-RBD-binding antibodies. The sequences we chosen based on their HC sequences also showed diversity in the LC phylogenetic tree (Supplementary Fig. 1). These 48 clones display a range of CDRH3 and CDRL3 lengths (Fig. 2B) and utilize an array of $\mathrm{V}$ genes in both the $\mathrm{HC}$ and LC (Fig. 2C), further confirming their diversity.

To determine which of these 48 non-RBD-binding antibodies target highly conserved epitopes, we used binding to the SARS-CoV-1 spike as a surrogate for epitope conservation. We designed the 48 scFvs constructs by fusing the antibody $\mathrm{HC}$ and $\mathrm{LC}$ variable regions to the yeast surface protein Aga2 $\mathrm{p}^{61-63}$ to enable yeast-surface display. To profile the scFv panel, we optimized production of biotinylated SARS-CoV-2 and other human coronavirus (hCoV) spike proteins (Supplementary Fig. 2A-D) and produced biotinylated versions of the SARS-CoV-2 and SARS-CoV-1 spike proteins. These were used to probe the yeast library by fluorescence flow cytometry (Fig. 3A). The complete 48-member library showed robust (82\%; Fig 3A) staining with the SARS-CoV-2 spike, consistent with the original antibody collection having been isolated from 


\section{Figure 2}
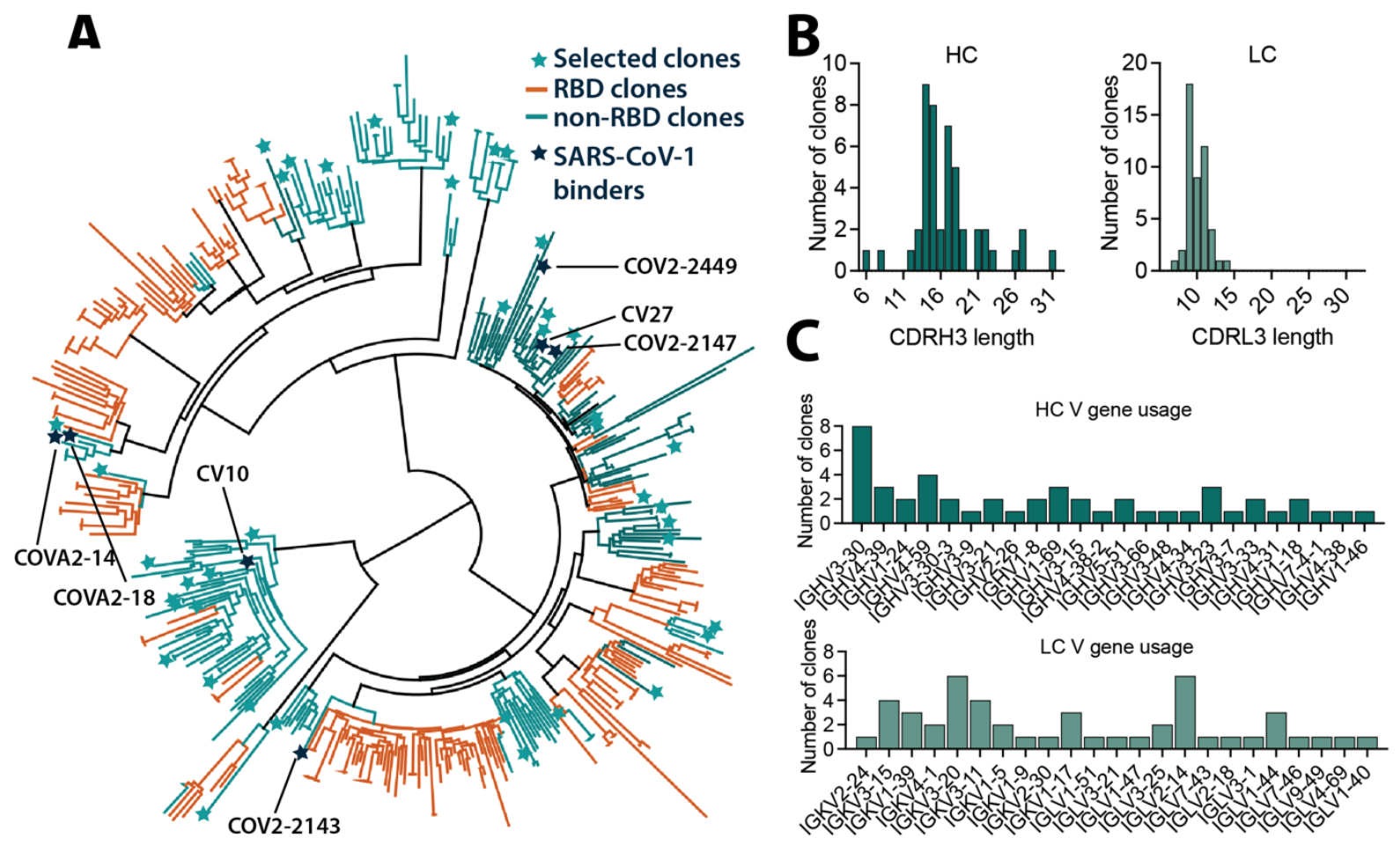

Figure 2 - non-RBD antibodies were selected to prioritize diversity. (A) A phylogenetic tree of 422 heavy chain sequences, from our curated library of 696 anti-SARS-COV-2 spike antibodies, was generated using Geneious Prime. Germline alleles not shown. 48 selected clones shown as stars. Histograms of the HC and LC (B) CDR3 lengths $(C) \vee$ gene usage from the 48 selected non-RBD clones indicated in $(A)$.

SARS-CoV-2 convalescent donors. The library had reduced (21\%; Fig 3A) staining with the SARS-CoV-1 spike. Consistent with the intention of the library, no clones bind to the RBD of SARS-CoV-2 (Fig. 3A).

Having identified 48 antibodies that bind outside the RBD, we next selected those that bind to highly conserved regions of the spike protein. To do this, we used fluorescence-activated cell sorting (FACS) $)^{64}$ with the SARS-CoV-1 spike protein as bait and identified ten sequences. We confirmed that the corresponding full-length IgG antibodies (Supplementary Fig. 3) bind to both SARS-CoV-2 and SARS-CoV-1 spike proteins by ELISA (Supplementary Fig. 4). Of the ten, seven clones were strong SARS-CoV-1 binders, confirmed by biolayer interferometry (BLI) (Fig. 3B). One clone, COV2-2449, also binds MERS and OC43 spike proteins (Supplementary Fig. 4 
bioRxiv preprint doi: https://doi.org/10.1101/2022.01.24.477625; this version posted January 25, 2022. The copyright holder for this preprint (which was not certified by peer review) is the author/funder, who has granted bioRxiv a license to display the preprint in perpetuity. It is made available under aCC-BY-NC-ND 4.0 International license.

and 5). Consistent with previous reports ${ }^{4,57-60}$, these antibodies were non-neutralizing in our assay (Supplementary Fig. 6).

We used BLI to characterize the epitopes of these seven antibodies in a binding competition assay. We loaded each antibody onto either SARS-CoV-2 or SARS-CoV-1 spike proteins, and then we tested for subsequent binding of each of the other antibodies (Fig. 3C). The results suggest that there are five primary epitopes, of which four are in a partially overlapping supersite (Fig. 3C) - likely corresponding to the extensive, continuous patch of highly conserved

\section{Figure 3}
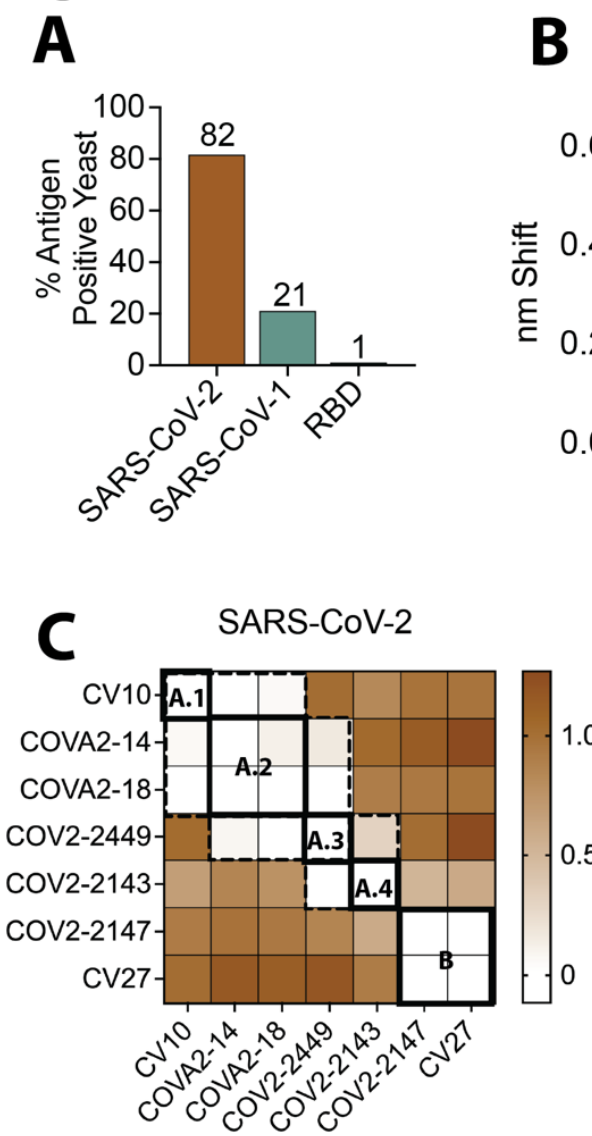

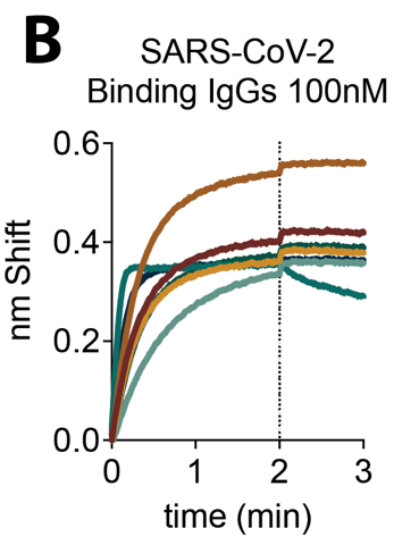

\section{SARS-CoV-1}

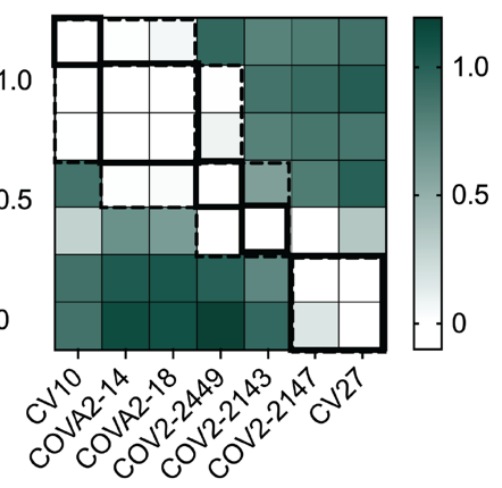

SARS-CoV-1

Binding IgGs 100nM

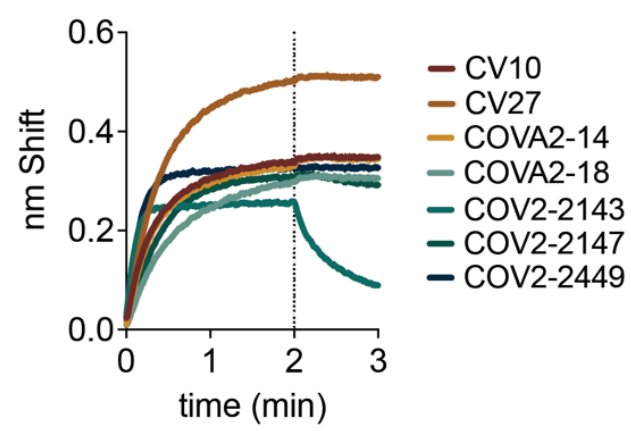

D

SARS-CoV-2

Binding Fabs $200 \mathrm{nM}$

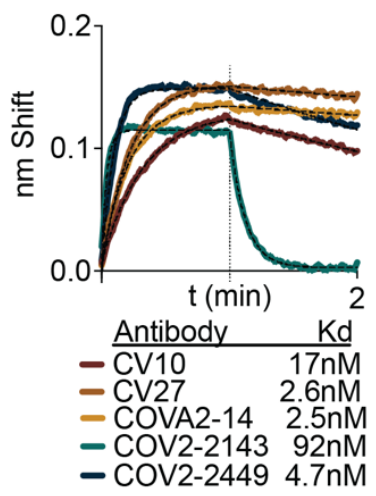

Figure 3-A subset of non-RBD SARS-CoV-2 antibodies bind SARS-CoV-1, a surrogate for epitope conservation. (A) A binding profile of the scFv-yeast library produced from the sequences identified in Fig. 1 and Supplementary Fig. 1. (B) BLI binding of identified cross-reactive clones expressed as IgGs binding at $100 \mathrm{nM}$ to SARS-CoV-2 spike (left) or SARS-CoV-1 spike (right). (C) BLI competition binding assay of the seven cross-reactive antibodies binding to SARSCoV-2 (left) and SARS-CoV-1 (right). White indicates no binding of the tested antibody, demonstrating the antibodies compete for binding. Antibodies which compete are surrounded by dotted lines, unique competition groups are surrounded by solid lines. The 5 unique competition groups are labeled on the SARS-CoV-2 binding competition map. Site A.1-A.4 is indicated as an overlapping supersite. Loading antibodies are indicated in columns and competing antibodies are indicated in rows. (D) Binding of antibodies FAb fragments at 200nM against SARS-CoV-2 spike. Hashed lines show $\mathrm{K}_{\mathrm{D}}$ fit determined using Prism. 
residues on the spike protein surface (Fig. 1A). Two sets of antibodies had identical epitopes the pair ${ }^{60}$ of COVA2-14 and COVA2-18, and the pair of CV27 and COV2-2147. This result is consistent with the phylogeny, which shows the antibodies in the two pairs clustered very closely together (Fig. 2A and Supplementary Fig. 1). The identification of five unique epitopes from the seven selected antibodies highlights the diversity in the initial starting library.

We selected five antibodies, one from each described epitope (Fig. 3D), and converted these non-neutralizing, cross-reactive antibodies into ReconnAbs by fusion to the ACE2 ectodomain, as the receptor-blocking component of the ReconnAb design. We designed the linker to be long enough to allow for simultaneous binding of both ACE2 to the RBD and the scFv, regardless of epitope, to the spike S2 domain (Fig. 4A and Supplementary Fig. 7). We joined the C-terminus of the scFv to the $\mathrm{N}$-terminus of ACE2, because the $\mathrm{N}$-terminal residue of the ACE2 ectodomain is adjacent to the SARS-CoV-2 RBD when bound. We also incorporated within the linker a hexa-histidine tag for purification and a TEV protease site to enable assessment of ReconnAb activity when its binding and inhibitory components are separated (Fig. 4A and Supplementary Fig. 7). We anticipated that ReconnAbs would bind to both a highly conserved site on the spike protein and simultaneously to the RBD through the ACE2 domain (Fig 4B). However, if cleaved at the TEV site, the intrinsically low-affinity ACE2 domain would not benefit from the affinity of the non-neutralizing antibody (Fig. 4B).

We expressed and purified the five ReconnAbs and used gel electrophoresis to confirm that TEV cleavage separated the ACE2 and scFv components (Fig. 4C). BLI experiments showed that TEV cleavage of the ReconnAb proteins reduced binding to both SARS-CoV-2 and SARSCoV-1 spike proteins (Fig. 4D), consistent with the lower affinity of monomeric ACE2 ${ }^{65}$. We then investigated the ability of the ReconnAbs to block ACE2 binding to the SARS-CoV-2 spike protein. ACE2 competition is often used as a surrogate for neutralization, as preventing ACE2 binding 
bioRxiv preprint doi: https://doi.org/10.1101/2022.01.24.477625; this version posted January 25, 2022. The copyright holder for this preprint (which was not certified by peer review) is the author/funder, who has granted bioRxiv a license to display the preprint in perpetuity. It is made available under aCC-BY-NC-ND 4.0 International license.

prevents the virus from interacting with target cells ${ }^{66}$. Indeed, uncleaved ReconnAbs show substantial interference with binding of an Fc version of human ACE2 (hFc-ACE2) whereas TEVcleaved ReconnAbs do not (Fig. 4E).

\section{Figure 4}

A

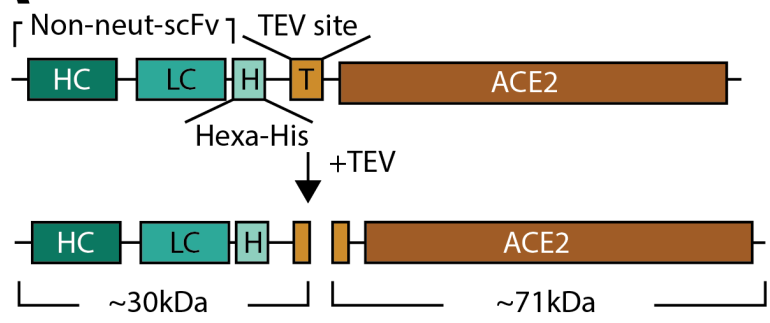

B
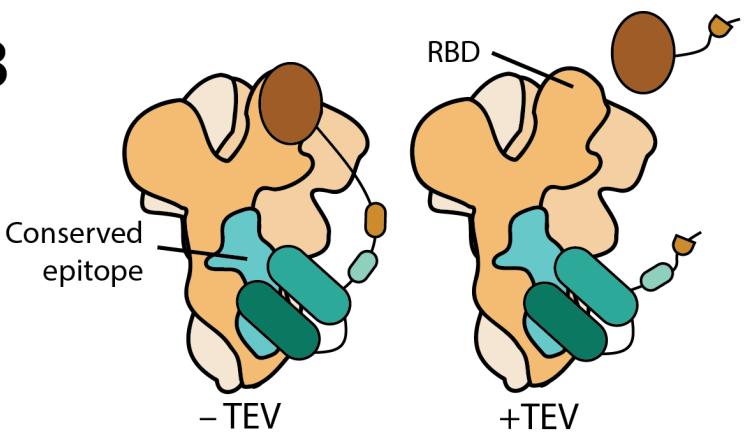

D

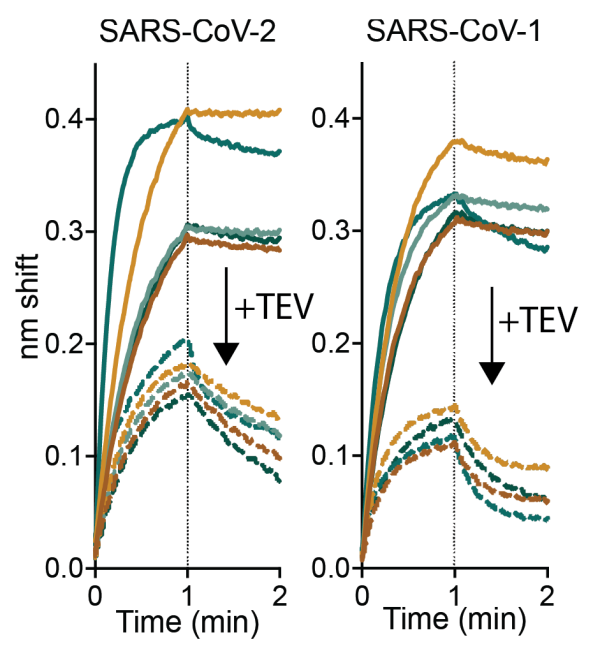

E ACE2 Competition
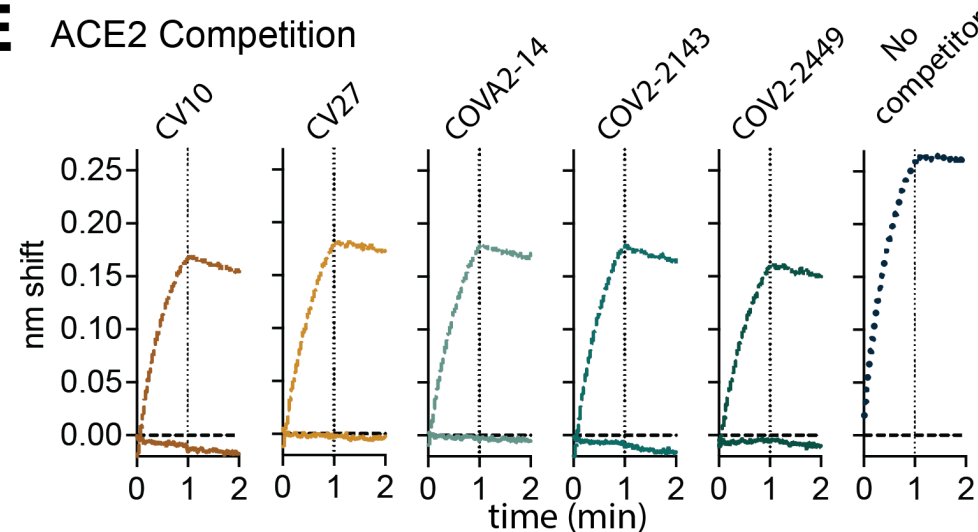

Figure 4 - scFv-based ReconnAbs tether ACE2 to cross-reactive, non-neutralizing antibodies. (A) A schematic of an scFv-based ReconnAb protein before and after TEV cleavage. Estimated molecular weights of cleavage products are shown beneath both. (B) schematic of ReconnAb activity and the dependence on the tether. The scFV binds to a conserved site and then ACE2 interacts with the RBD. Upon TEV cleavage, the ACE2 has lower apparent affinity and does not bind the RBD (right). Conserved sites shown as teal, remainder of spike monomers shown as tints of brown.

(C) SDS-PAGE demonstrates ReconnAbs are readily cleaved by TEV. 1. Full-length ReconnAb, 2. ACE2, 3. scFv.

(D) BLI binding of uncleaved and TEV-cleaved ReconnAbs to either SARS-CoV-2 spike (left) or SARS-CoV-1 spike (right) show a reduction in binding upon TEV cleavage. (E) BLI binding of hFc-ACE2 to SARS-CoV-2 spike which have been pre-associated with ReconnAbs either uncleaved (solid lines) or cleaved (hashed lines) show TEVcleaved ReconnAbs do not compete with hFc-ACE2 binding. Binding of hFc-ACE2 without competitor shown on the right (dotted line). 
We next investigated if ReconnAbs were able to neutralize lentiviral pseudoviruses corresponding to the SARS-CoV-2 VOCs and found that all ReconnAbs neutralized all VOCs some showing nanomolar potency against Omicron (Fig. 5). Consistent with its lower affinity (Fig. 3D), COV2-2143-ACE2 had the weakest neutralization of the tested ReconnAbs (Fig. 5). COV22449-ACE2 showed the least deviation in neutralization potency between variants, consistent with its epitope being the most highly conserved (Supplementary Fig. 4 and 5). Importantly, the TEVproteolyzed versions of the ReconnAbs did not confer the same neutralizing potency as their uncleaved counterparts (Fig. 5), demonstrating that the separate components are not working synergistically, but that the tether is essential for the ReconnAb components to work cooperatively.

Two ReconnAbs, CV10-ACE2 and COV2-2449-ACE2, were of particular interest as they showed broad-spectrum neutralization (Fig. 5) and did not have overlapping epitopes (Fig. 3C). We postulated that a bifunctional IgG-ReconnAb containing both CV10 and COV2-2449 would

\section{Figure 5}

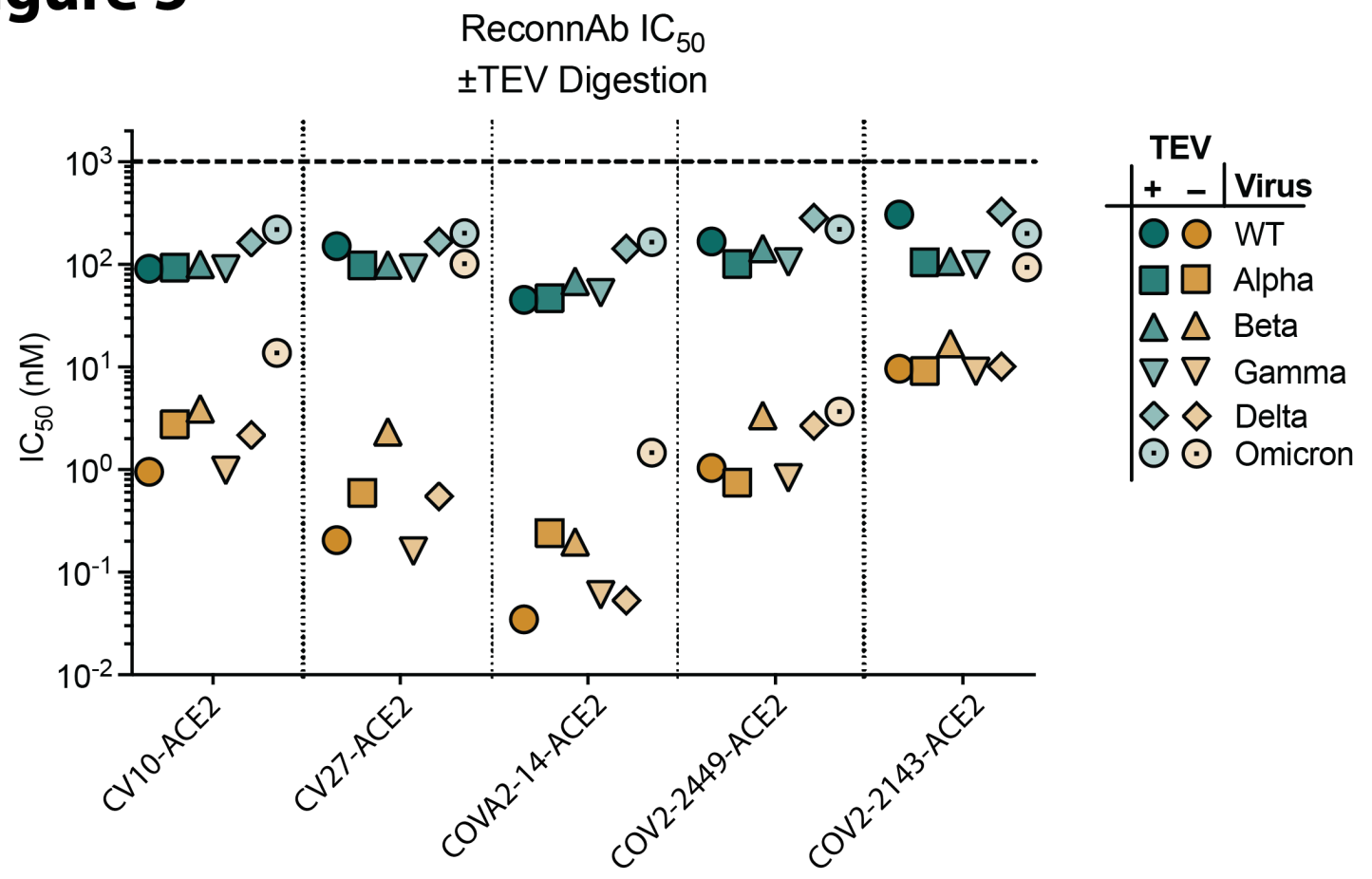

Figure 5 - Intact ReconnAbs (orange) show broad spectrum neutralization of SARS-CoV-2 VOCs. Inhibition is markedly reduced upon TEV cleavage (teal). Pseudoviral $50 \%$ inhibitory concentration (IC 50 ) for ReconnAbs (bottom) against a range of SARS-CoV-2 VOCs with and without TEV cleavage. $\mathrm{IC}_{50}$ values shown are the average of two independent experiments. 
make viral escape even less likely. To produce a bifunctional IgG-ReconnAb, we utilized the CrossMAb platform ${ }^{67-69}$ and tethered ACE2 to the LC of only one of the lgG arms (Fig. 6A, B). This allows, as with the scFv-ACE2 fusions, that the stoichiometry be only a single ACE2 per ReconnAb, such that ACE2 remains monovalent before and after TEV-cleavage.

We expressed and purified the CV10-2449-ACE2-CrossMAb (Fig. 6B) and found that it bound to SARS-CoV-2 as expected (Fig 6C). As well, the uncleaved CrossMAb competed substantially with ACE2 (Supplementary Fig. 8). Dependent on the presence of the tether, the CV10-2449-ACE2-CrossMAb neutralized all SARS-CoV-2 VOCs, including Omicron, at subnanomolar concentrations (Fig. 6D). Taken together, the results described here lay a foundation for the development ReconnAbs as a novel class of broadly neutralizing therapeutics.

\section{Figure 6}

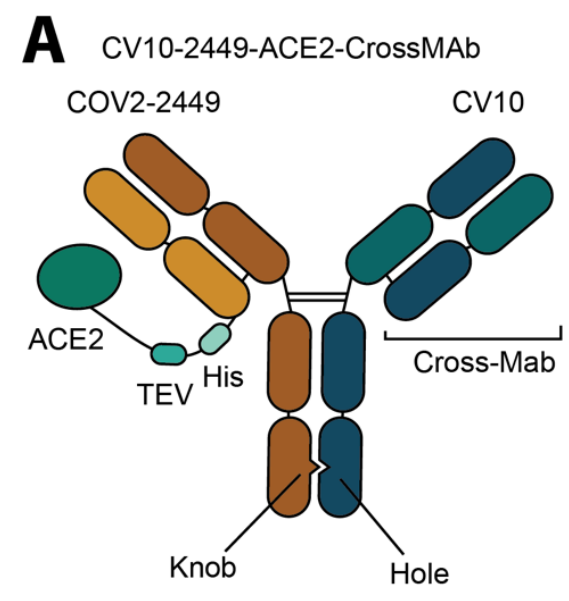

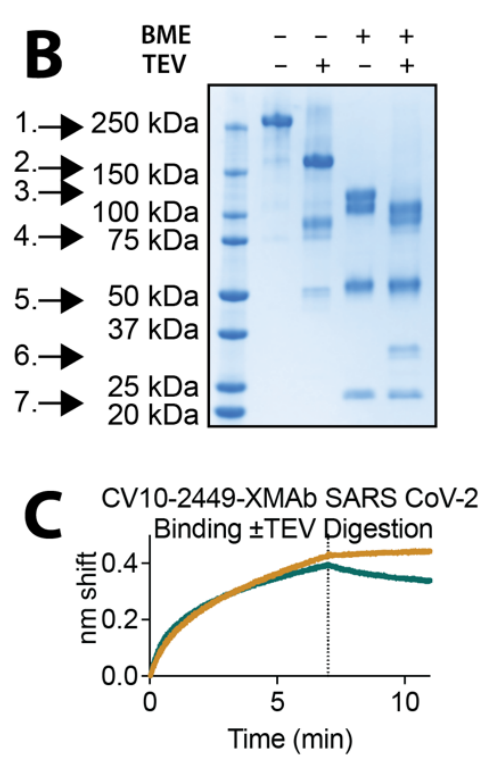

D

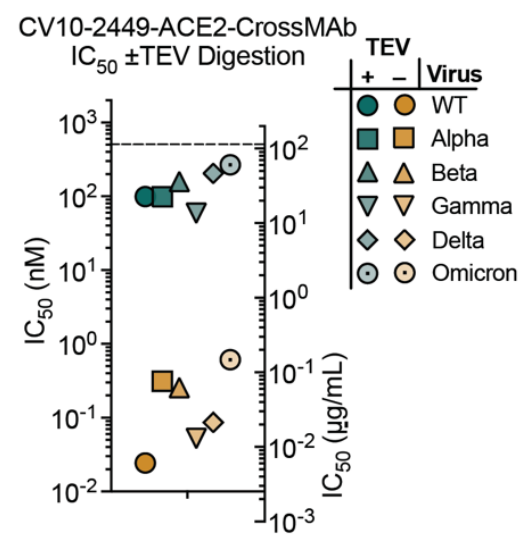

Figure 6 - A bifunctional IgG ReconnAb shows potent neutralization of SARS-CoV-2 VOCs. (A) A schematic representation of the CV10-2449-ACE2-CrossMAb indicates linkage of ACE2 and bifunctional Fab arms. (B) The CV10-2449-ACE2-CrossMAb ReconnAb contains all designed components by SDS-PAGE, assayed before or after TEV cleavage and with or without 2-mercaptoethanol (BME). 1. Full-length ReconnAb, 2. Cleaved CrossMAb CV102449 IgG, 3. COV2-2449-LC-ACE2 fusion, 4. ACE2 (reduced ACE2 shows double banding), 5. HC, 6. Cleaved 2449LC with linker, 7. CV10 LC. (C) BLI binding of CV10-2449-ACE2-CrossMAb (brown) or the TEV cleaved form (teal) to SARS-CoV-2 spike. Binding is reduced upon TEV cleavage. (D) Pseudoviral $50 \%$ inhibitory concentration $\left(\mathrm{IC}_{50}\right)$ for CV10-2449-ACE2-CrossMAb against a range of SARS-CoV-2 VOCs with and without TEV cleavage. $I_{50}$ values shown are the average of two independent experiments. 


\section{Discussion}

Traditionally, the discovery of therapeutic biologics against infectious diseases has focused on identifying agents with neutralizing activity. We demonstrate here using ReconnAbs, that cross-reactive, non-neutralizing antibodies - which have been often largely overlooked - can be powerful reagents in the creation of potent, broad-spectrum anti-viral agents.

ReconnAbs have two main components: a binding component - the non-neutralizing antibody that binds with high-affinity to a conserved region on the spike protein - and an inhibitory component, in our case, the ACE2 domain ${ }^{70,71}$. Since therapeutics containing ACE2 run the risk of eliciting autoimmunity in humans, our use of ACE2 as the inhibitory component represents a proof-of-concept of the ReconnAb design. The ACE2 module could be replaced by other neutralizing components such as ACE2 domains with enhanced RBD-binding activity ${ }^{72-74}$, aptamers $^{75,76}$, or RBD-directed $m A b s^{1-9,46,56-60,77}$. Future ReconnAb designs could also target the interaction with dipeptidyl peptidase 4 (DPP4), a receptor for other coronaviruses ${ }^{78}$, furthering their breadth.

Improvements could also be made to the conserved, non-neutralizing antibodies. Our library of SARS-CoV-2 non-RBD antibodies was derived from sequences early in the COVID-19 pandemic, which is relatively small in scope. The library does not contain, for instance, any vaccine-derived antibodies, which are known to include cross-reactive, non-neutralizing antibodies $^{49}$. Future iterations of this work could start with much larger libraries ${ }^{57}$, with the potential to identify antibodies and/or nanobodies that target the most highly conserved epitopes and that are least likely to undergo mutational escape ${ }^{79}$. Although we have focused on non-neutralizing antibodies, neutralizing antibodies that bind to conserved epitopes might also be useful as the conserved component of ReconnAbs. Other features like linkage locations and length, fusion 
partners, and modifications to the Fc domains can be tuned in subsequent ReconnAb designs, and will likely play an important role in their future conversion to therapeutics ${ }^{23-25}$.

Compared to neutralizing epitopes, highly conserved, non-neutralizing epitopes are less likely in theory to be subject to immune pressure since their mutations do not affect the ability of the virus to infect cells. Omicron provides strong evidence that SARS-CoV-2 viral evolution responds to immune pressure by mutating neutralizing epitopes (Fig.1 $)^{10,11,34,35}$. ReconnAbs demonstrate the powerful utility of a non-active component, if it targets a highly conserved epitope, in the development of therapeutics.

Finally, we anticipate that interrogation of existing antibody libraries for highly conserved, non-neutralizing binders will facilitate production of ReconnAbs, not just for SARS-CoV-2 but also for other viruses like HIV-1, influenza ${ }^{80}$, or other human coronaviruses. We see ReconnAbs as having utility not only in the current pandemic, but also in mitigating the impact of future pandemics. Strategic stockpiles of customized ReconnAbs and rapid administration in a pandemic setting could alleviate the initial impact of a new pathogen, allowing time for other therapeutics and countermeasures to be put into place. 


\section{Declaration of Interests:}

P.A.-B.W., E.W. and P.S.K. are named as inventors on a provisional patent application applied

for by Stanford University and the Chan Zuckerberg Biohub on coronavirus neutralizing compositions and associated methods.

\section{Acknowledgments:}

We thank J. Bloom and A. Greaney for plasmids and cells related to viral neutralization assays, J. DeRisi, K. Zorn, L. Matthew and M. Ott for Omicron-related plasmids, and I. Anderson at Stanford PAN facilities for rapid production of oligos utilized throughout this work. We are also grateful to T. Bruun and M. Filsinger Interrante and other members of the Kim Lab for fruitful discussions and helpful comments on earlier versions of this manuscript. The CMV/R expression vectors for IgG production were received from the NIH AIDS Reagent Program. This work was supported by the Virginia \& D.K. Ludwig Fund for Cancer Research, the Frank Quattrone and Denise Foderaro Family Research Fund, and the Chan Zuckerberg Biohub. 


\section{Methods}

\section{Determination of sequence conservation in SARS-CoV-2 spike}

Sequences of 42 of spike proteins, with between $30 \%-90 \%$ sequence conservation compared to SARS-CoV-2, as well as RaTG13 were aligned using the $6 \mathrm{VXX}$ sequence ${ }^{26}$ as a template. The sequences were aligned using Clustal $\mathrm{Omega}^{30}$ to develop a multiple sequence alignment (MSA). The MSA was uploaded onto the Consurf server ${ }^{27-29}$ for overlay onto the $6 \mathrm{VXX}$ structure on chain A. The resultant chain A was recolored based on conservation and replicated to replace chains $B$ and $C$. The sequence alignment was again produced using MUSCLE ${ }^{31}$ and sequence identity was calculated using Geneious (Geneious Prime 2022.0.1). The alignment was truncated at residue 1213 where the sequence alignment dropped to only 9 sequences. The sequences used were: 6VXX, UniRef90_U5NJG5, _L7UP8, _A0A7U3W1C7, _K9N5Q8, _A0A2I6PIW5,_A0A3Q8AKM0,_U5WHZ7,_A0A5H2WTJ3,_A0A0U1WJY8,_A0A166ZND9, _A0A678TRJ7,_A0A2R4KP93,_A0A2Z4EVK1,_A0A7R6WCE7,_E0ZN36,_A0A6M3G9R1, _F1DAZ9, _A0A0U1UYX4, _A0A2R3SUW7, _A0A2Z4EVN5, _A0A2Z4EVN2, _U5LMM7, _A0A5Q0TVR4,_E0XIZ3,_A0A023Y9K3,_A0A2R4KP86,_A0A088DJY6,_A0A7G6UAJ9, _S4X276,_A0A4Y6GL90,_A3EXG6,_F1BYL9,_E0ZN60,_A0A0K1Z054,_A0A0U1WHI2, and NCBI accession numbers: YP_009047204.1, QLR06867.1, AAK32191.1, AGZ48828.1, AAT84362.1, QHR63300.2, ABD75513.1, YP_003767.1.

\section{Library Design}

A library of antibodies directed against SARS-CoV-2 Spike (S) protein was developed using paired antibody sequences, meaning antibody sequences for which the heavy and light chain are both known, from the Coronavirus Antibody Database, CoV-AbDab ${ }^{57}$. All antibody 
sequences from convalescent COVID-19 donors which had been deposited before July $9^{\text {th }} 2021$, were inserted into a table, categorized by their binding to the SARS-CoV-2 RBD portion of the spike protein or to a non-RBD portion of SARS-CoV-2 spike. Antibodies which were cataloged for non-RBD binding were preferentially identified, resulting in a total of 385 paired antibody sequences. For these non-RBD binding antibodies, the amino acid sequences of the corresponding heavy chain and light chain V-genes and CDR3 regions, already compiled from the Coronavirus Antibody Database, were imported into Geneious Prime v2021.1.1 (a bioinformatics software; geneious.com). Using Geneious Prime, the heavy chain sequences and light chain sequences were separately analyzed to produce phylogenetic trees. For these phylogenetic trees, RBD binding antibodies were also included to ensure selection of antibody sequences that were both non-RBD binding and clearly distinct from RBD-binding sequences. 371 RBD-binding antibody, 59 germline antibody, and 325 non-RBD binding antibody nucleic acid sequences of the corresponding heavy chain and light chain genes were imported, for a total of 755 heavy chain and light chain sequences (696 excluding germline antibodies). The sequences were first aligned using the MUSCLE algorithm, and then two phylogenetic trees were made, both using PhyML 3.3.20180621. The sequence similarities used to produce phylogenetic trees account for antibody germlines, CDR lengths, and amount of somatic hypermutation. After producing phylogenetic trees based on the heavy chain and light chain sequences, a total of 48 sequences were identified based on their location in the phylogeny. Distinct clusters, composed of only non-RBD sequences, on the heavy chain phylogenetic trees were noted, and a single representative sequence was selected from each, chosen to also include distinct light chain sequences whenever possible.

\section{$\underline{\text { scFv design }}$}

The sequences of these 48 antibodies were then converted into scFv sequences by linking the $\mathrm{HC}$ variable region to the LC variable region with a G4S-3 linker (GGGGSGGGGSGGGGS). 
All scFvs were designed in the order: signal sequence-HC-G4-S-3-LC. This vector also contained the HVM06_Mouse Ig heavy chain V region 102 signal peptide (MGWSCIILFLVATATGVHS) to allow for protein secretion and purification from the supernatant. Following construct design, the plasmids were ordered with the sequences inserted at the Xhol and Nhel sites in the pTwist CMV BetaGlobin vector (Twist Biosciences).

\section{Library Production}

$4 \mu \mathrm{g}$ of pPNL6 vector in Cut Smart buffer was digested using $1 \mu \mathrm{l}$ of Nhel HF and BamHI HF (NEB Biolabs) at $37^{\circ} \mathrm{C}$ for $1 \mathrm{~h}$. Digested plasmid was then gel extracted using Thermofisher Scientific Gel Extraction Kit. Equimolar aliquots of each scFv plasmid were pooled and the resultant pool was amplified using primers which annealed to the hexa-his Tag (reverse primer) or signal peptide (forward primer) and had a 50bp overlap with the pPNL6 vector digested with Nhel and BamHI. The pooled amplification was gel extracted to ensure it was the correct size. Yeast were prepared by first streaking a YPAD plate and incubating for 2-3 days until a single colonies were identifiable. A single colony was inoculated in $5 \mathrm{~mL}$ of YPAD overnight shaking at $30^{\circ} \mathrm{C}$. Cultures were harvested into 6 tubes and pelleted. Yeast were resuspended in electroporation buffer (10 mM Tris Base, $250 \mathrm{mM}$ sucrose, $2 \mathrm{mM} \mathrm{MgCl}$ ) containing the gel extracted library amplification and digested pPNL6 vector. This mixture was then pulsed and the electroporated yeast were recovered in SD-CAA media overnight $\left(30^{\circ} \mathrm{C}\right.$ shaking). These yeast were then induced by a $1: 10$ dilution into SG-CAA media and grown at $20^{\circ} \mathrm{C}$ shaking for $2-3$ days.

\section{Yeast Binding}

Following induction in SG-CAA shaking for 2-3 days at $20^{\circ} \mathrm{C}$, the yeast library, expressing surface exposed scFvs, was incubated for 15 mins with a dilution of preformed baits. Baits were formed by mixing biotinylated baits and streptavidin 647 (Jackson Immunoresearch) at a 4:1 ratio. For example, $250 \mathrm{nM}$ bait would be produced by incubation of $250 \mathrm{nM}$ biotinylated antigens and 
62.5 nM streptavidin 647. Yeast were flowed with two colors of "bait," the first (FITC) stains for a c-myc tag. The c-myc tag is a surrogate for expression as the scFv constructs in the pPNL6 vector contain an in-frame C-terminal c-myc tag. So, any yeast which are c-myc positive are displaying full-length antibodies. The second color bait (Alexa Flour 647 - APC channel) stains for the antigen-target of the scFv. To make the stain, streptavidin with an Alexa Flour 647 tag is incubated with biotinylated bait protein. This complex is then used to stain the yeast. Any yeast which are positive for Alexa Flour 647, are then binding to the protein antigen. Yeast were spun down and resuspended in in $50 \mu \mathrm{l}$ PBSM containing the respective concentration of tetrameric bait. After 15mins cells were then washed $1 \mathrm{x}$ with PBSM and then resuspended in 50 $\mu$ L PBSM containing $1 \mu \mathrm{l}$ of anti-c-myc FITC (Miltenyi) for 15 mins. Samples were then washed $2 x$ with PBSM and then resuspended in $50 \mathrm{uL}$ of PBSM. These samples were flowed (Accuri C6 flow cytometer) and the percent antigen positive was determined as the ratio of antigen positive cells divided by all cells expressing scFv (c-myc positive) multiplied by 100 . Gates were set such that $\sim .5 \%$ of yeast were antigen positive in the streptavidin alone control.

\section{$\underline{\text { Yeast Sorts }}$}

The yeast library was incubated with $125 \mathrm{nM}$ of tetrameric SARS-CoV-1 and $1 \mu \mathrm{l}$ of antic-myc FITC (Miltenyi) for 1 hour. Samples were then washed $2 x$ with PBSM and then resuspended in $50 \mu \mathrm{l}$ PBSM. These libraries were then sorted on an FACSAria llu using the Stanford FACS Facility (Stanford CA). The samples were gated such that all antigen positive cells were collected (gates set such that $\sim 0 \%$ anti-cmyc FITC alone controls fell within the gate). Two populations were sorted, a hi-gate, consisting of the highest intensity binders (3.8\% of all cells), and a low-gate, consisting of all other antigen positive cell $(3.7 \%$ of all cells). Cells were sorted directly into tubes containing $4 \mathrm{~mL}$ of SD-CAA media. These sorted libraries were grown for 1 day at $30^{\circ} \mathrm{C}$ shaking in SD-CAA media and then $300 \mu$ of the cultures were miniprepped (Zymo Research) following the manufacturer's protocol. Miniprepped DNA was transformed into 
STELLAR Competent Cells (Clontech) and plated on carbenicillin LB agar plates (as per pPNL6's resistance marker). E. coli cells that grow should, theoretically, contain only a single sequence from each of the yeast that were sorted above. $10 \mathrm{E}$. coli colonies from the hi-gate and $20 \mathrm{E}$. coli colonies from the low-gate sort were sent for sequencing (Sequetech, Mountain View CA). The sequences were then analyzed by sequence alignment using SnapGene software.

\section{$\underline{\text { Constructs }}$}

$\underline{\text { scFv-ACE2 fusion proteins }}$

scFvs identified as cross-reacting with SARS-CoV-1 and falling into a unique epitope (CV10, CV27, COVA2-14, COV2-2449, COV2-2143) sort were cloned into the pTwist CMV BetaGlobin vector such that they contained a linker (GGSGSHHHHHHASTGGGSGGPSGQAGAAASEENLYFQGSLFVSNHAYGGSGGEARV) followed by the ectodomain of human ACE2.

\section{Light chain (LC) and LC-ACE2 fusion proteins}

Antibody sequences were cloned into the CMV/R plasmid backbone for expression under a CMV promoter. The antibodies variable LC were cloned between the CMV promoter and the bGH poly(A) signal sequence of the CMV/R plasmid to facilitate improved protein expression. The variable region was cloned into the human IgG1 backbone with a kappa LC. This vector also contained the HVM06_Mouse (P01750) Ig heavy chain V region 102 signal peptide to allow for protein secretion and purification from the supernatant. The light chains from the scFvs from the above-described SARS-CoV-1 sort were cloned into the CMV/R vector in frame with the kappa LC. For COV2-2449 the LC was additionally cloned such that there was a C terminal linker (GGSGSHHHHHHASTGGGSGGPSGQAGAAASEENLYFQGSLFVSNHAYGGSGGEARV)) followed by the ectodomain of human ACE2. 


\section{$\underline{\text { Heavy Chain }(\mathrm{HC}) \text { lgG plasmids }}$}

Antibody sequences were cloned into the CMV/R plasmid backbone for expression under a CMV promoter. The antibodies variable $\mathrm{HC}$ were cloned between the CMV promoter and the bGH poly $(A)$ signal sequence of the CMV/R plasmid to facilitate improved protein expression. The variable region was cloned into the human $\lg G 1$ backbone. This vector also contained the HVM06_Mouse (P01750) Ig heavy chain V region 102 signal peptide to allow for protein secretion and purification from the supernatant. The heavy chains from the scFvs from the above-described SARS-CoV-1 sort were cloned into the CMV/R vector in frame with $\mathrm{HC}$ constant regions.

\section{$\underline{\mathrm{hCoV} \text { spike proteins constructs }}$}

Spike proteins from six hCoVs were cloned into a pADD2 vector between the rBeta-globin intron and $\beta$-globin poly $(A)$. A total of 48 constructs were cloned and tested containing either a $C$ terminal truncation or not, a foldon or GCN4 trimerization domain, and containing an Avi tag or not. Each set of eight proteins was produced for the 6 hCoV spike proteins from SARS-CoV-2, SARS-CoV-1, MERS, 229E, NL63, and OC43. Depictions of the constructs and linkers produced are shown in supplementary Fig. 2.

\section{$\underline{\text { Lentivirus plasmids }}$}

Plasmids encoding the full-length spike proteins with native signal peptides were cloned into the background of the HDM-SARS2-Spike-delta21 plasmid (Addgene Plasmid \#155130). This construct contains a 21 amino acid c-terminal deletion to promote viral expression. The SARS-CoV-1 spike was used with an 18 amino acid C-terminal deletion. The other viral plasmids that were used were previously described (doi: 10.3390/v12050513). They are: pHAGE-Luc2IRS-ZsGreen (NR-52516), HDM-Hgpm2 (NR-52517), pRC-CMV-Rev1b (NR-52519), and HDMtat1b (NR-52518). 


\section{DNA Preps}

The 48 spike protein constructs from the hCoVs were mirA prep using ThermoFisher GeneJET plasmid miniprep kit. $8 \mathrm{~mL}$ of $E$. Coli containing the constructs were harvested by centrifugation and $200 \mu \mathrm{L}$ of freshly made resuspension buffer was added to each clone. $200 \mu \mathrm{L}$ was then added of lysis buffer followed by inversion and then $300 \mu \mathrm{L}$ of neutralization buffer was added. Lysed E. Coli was then centrifuged at $>18,000 \mathrm{~g}$ for $10 \mathrm{~min}$. The supernatant was transferred to a tube containing $580 \mu \mathrm{L}$ of $100 \% \mathrm{EtOH}$. The EtOH solution was then added to a geneJET plasmid miniprep column and the regular wash steps and elution steps were followed. MirA preps resulted in significantly more plasmid production and allowed for small scale transfection of the 48 clones tested. For the FL-GCN4-Avi-His expression tests and protein production, all samples were maxi prepped from $200 \mathrm{~mL}$ of E. Coli using NuceloBond Xtra Maxi Kit per the manufacturers recommendations (Macherey-Nagel). All scFv-ACE2, CrossMAb, antibody, hFc-ACE2, and Lentiviral plasmids were maxi prepped in the same fashion.

\section{Protein Production}

Protein Expression. All proteins were expressed in Expi293F cells. Expi293F cells were cultured in media containing 66\% Freestyle/33\% Expi media (ThermoFisher) and grown in TriForest polycarbonate shaking flasks at $37^{\circ} \mathrm{C}$ in $8 \% \mathrm{CO} 2$. The day before transfection cells were spun down and resuspended to a density of $3 \times 10^{6} \mathrm{cells} / \mathrm{mL}$ in fresh media. The following day cells were diluted and transfected at a density of approximately $3-4 \times 10^{6}$ cells $/ \mathrm{mL}$. Transfection mixtures were made by adding the following components: mirA-prepped or maxi-prepped DNA, culture media, and FectoPro (Polyplus) would be added to cells to a ratio of $.5-.8 \mu \mathrm{g}: 100 \mu \mathrm{L}: 1.3 \mu \mathrm{L}: 900 \mu \mathrm{L}$. For example, for a $100 \mathrm{~mL}$ transfection, $50-80 \mu \mathrm{g}$ of DNA would be added to $10 \mathrm{~mL}$ of culture media and then $130 \mathrm{uL}$ of FectoPro would be added to this. Following mixing and a $10 \mathrm{~min}$ incubation, the resultant transfection cocktail would be added to $90 \mathrm{~mL}$ of cells. The cells were harvested 3-5 
days post-transfection by spinning the cultures at $>7,000 \mathrm{xg}$ for 15 minutes. Supernatants were filtered using a $0.22 \mu \mathrm{m}$ filter. To determine hCoV protein expression, spun-down Expi293F supernatant was used without further purification. For proteins containing a biotinylation tag (AviTag) Expi293F cells containing a stable BirA enzyme insertion were used, resulting in spontaneous biotinylation during protein expression.

Protein purification - Fc Tag containing proteins.

All proteins containing an Fc tag (for example, IgGs, CrossMAb-Ace2 fusions, hFc-ACE2) were purified using a $5 \mathrm{~mL}$ MAb Select Sure PRISM ${ }^{\mathrm{TM}}$ column on the AKTA pure FPLC. (Cytiva). Filtered cell supernatants were diluted with 1/10th volume 10x Phosphate Buffered Saline (PBS). The AKTA system was equilibrated with, A1 - 1xPBS, A2 - 100 mM Glycine pH 2.8, B1 - 0.5M $\mathrm{NaOH}$, Buffer line - 1xPBS, Sample lines - H2O. The protocol washes the column with A1, followed by loading of the sample in Sample line 1 until air is detected in the air sensor of the sample pumps, followed by 5 column volume washes with $\mathrm{A} 1$, elution of the sample by flowing of $20 \mathrm{~mL}$ of $\mathrm{A} 2$ (directly into a $50 \mathrm{~mL}$ conical containing $2 \mathrm{~mL}$ of $1 \mathrm{M}$ Tris $\mathrm{pH} 8.0$ ) followed by 5 column volumes A1, B1, A1. The resultant Fc-containing samples were concentrated using 50 or $100 \mathrm{kDa}$ cutoff centrifugal concentrators. Proteins were buffer exchanged using a PD-10 column (SEPHADEX) which had been preequilibrated into $20 \mathrm{mM}$ HEPES, $150 \mathrm{mM} \mathrm{NaCl}$. IgGs used for competition, binding, and neutralization experiments were not further purified. CrossMAb-ACE2 fusions were then further purified using the $\$ 6$ column on the AKTA.

\section{Protein purification - His-tagged proteins.}

All proteins not containing an Fc tag (for example, scFvs and scFv fusions, and FL Spike trimers from hCoVs polypeptide antigens) were purified using HisPur ${ }^{\mathrm{TM}}$ Ni-NTA resin (ThermoFisher). Cell supernatants were diluted with $1 / 3$ rd volume wash buffer ( $20 \mathrm{mM}$ imidazole, $20 \mathrm{mM}$ HEPES $\mathrm{pH} 7.4,150 \mathrm{mM} \mathrm{NaCl}$ ) and the Ni-NTA resin was added to diluted cell 
supernatants. For all mixtures not containing hCoV spike protein, the samples were then incubated at $4^{\circ} \mathrm{C}$ while stirring overnight. hCoV spike proteins were incubated at room temperature. Resin/supernatant mixtures were added to chromatography columns for gravity flow purification. The resin in the column was washed with wash buffer $(20 \mathrm{mM}$ imidazole, $20 \mathrm{mM}$ HEPES $\mathrm{pH} 7.4,150 \mathrm{mM} \mathrm{NaCl}$ ) and the proteins were eluted with $250 \mathrm{mM}$ imidazole, $20 \mathrm{mM}$ HEPES pH 7.4, 105mM NaCl. Column elutions were concentrated using centrifugal concentrators (50 kDa cutoff for scFv-ACE2-fusions, and $100 \mathrm{kDa}$ cutoff for trimer constructs), followed by sizeexclusion chromatography on a AKTA Pure system (Cytiva). AKTA pure FPLC with a Superdex 6 Increase gel filtration column (S6) was used for purification. $1 \mathrm{~mL}$ of sample was injected using a $2 \mathrm{~mL}$ loop and run over the $\mathrm{S} 6$ which had been preequilibrated in degassed $20 \mathrm{mM}$ HEPES, 150 $\mathrm{mM} \mathrm{NaCl}$ prior to use. Biotinylated antigens were not purified using the AKTA pure.

\section{$\underline{\text { TEV Digestion }}$}

TEV digestion of scFv-ACE2 fusions. $2 \mu \mathrm{L}$ of TEV protease (New England BioLabs) was added per $200 \mu \mathrm{L}$ of scFv-ACE2 fusions at $\sim 4 \mu \mathrm{M}$ in $20 \mathrm{mM}$ HEPES, $150 \mathrm{mM} \mathrm{NaCl}$. The reaction was left to incubate overnight at $30^{\circ} \mathrm{C}$. Extent of cleavage was determined by and SDS-PAGE analysis on 4-20\% Mini-PROTEAN® TGX ${ }^{\mathrm{TM}}$ protein gels stained with GelCode ${ }^{\mathrm{TM}}$ Blue Stain Reagent (ThermoFisher). TEV digestion of CrossMAb-ACE2 fusions. $3 \mu \mathrm{L}$ of TEV protease (New England BioLabs) was added per $200 \mu \mathrm{L}$ of CrossMAb-ACE2 fusions at $\sim 2 \mu \mathrm{M}$ in $20 \mathrm{mM}$ HEPES, $150 \mathrm{mM} \mathrm{NaCl}$. The reaction was left to incubate overnight at $30^{\circ} \mathrm{C}$. Extent of cleavage was determined by and SDS-PAGE analysis on 4-20\% Mini-PROTEAN® TGX ${ }^{\mathrm{TM}}$ protein gels stained with GelCode ${ }^{\mathrm{TM}}$ Blue Stain Reagent (ThermoFisher).

\section{$\underline{\text { FAb Production from lgGs }}$}

$1 / 10$ volume of $1 \mathrm{M}$ Tris, $\mathrm{pH} 8$ was added to $\mathrm{lgGs}$ at $\sim 2 \mathrm{mg} / \mathrm{mL}$ in PBS. $2 \mu \mathrm{L}$ of a $1 \mathrm{mg} / \mathrm{mL}$ stock of Lys-C (stock stored at -70C) was added for each mg of human IgG1 and digested for 1 
hour at $37{ }^{\circ} \mathrm{C}$ with moderate rotation. Digested FAbs were purified by SP/AKTA using $50 \mathrm{mM}$ $\mathrm{NaOAc}$, pH5 with gradient $\mathrm{NaCl}$ elution (using $50 \mathrm{mM} \mathrm{NaOAc}+1 \mathrm{M} \mathrm{NaCl}, \mathrm{pH} 5$ ). $\mathrm{FAb}$ fractions were pooled and dialyze against 1x PBS and concentrated using 30kDa concentrators. Purified FAbs were stored at $-80{ }^{\circ} \mathrm{C}$.

\section{Biolayer Interferometry Binding}

Biolayer interferometry (Octet) Binding Experiments - hCoV expression testing. All reactions were run on an Octet Red 96 and samples were run in PBS with $0.1 \%$ BSA and $0.05 \%$ Tween 20 (octet buffer). hCoVs supernatants were assessed for binding using anti-Penta His (His1K) tips were used. These tips are designed to bind specifically to a penta-His tag on proteins. For this experiment, tips were baselined in a blank well and then associated in the wells containing $50 \mu \mathrm{L}$ of hCoV expression media and $150 \mu \mathrm{L}$ octet buffer. Response values (I.E. peak reached after 5 mins of association) was determined using the Octet data analysis software. Final data analysis was done in Prism.

Biolayer interferometry (Octet) Binding Experiments IgG binding. All reactions were run on an Octet Red 96 and samples were run in PBS with $0.1 \%$ BSA and $0.05 \%$ Tween 20 (octet buffer). IgGs produced from the scFvs from the above sort were assessed for binding using streptavidin (SA) biosensors (Sartorius/ForteBio) loaded to a threshold of 0.8nm of SARS-CoV2, SARS-CoV-1, MERS, and OC43 biotinylated spike proteins. Tips were then washed and baselined in wells containing only octet buffer. Samples were then associated in wells containing 100nM IgG. A control well which loaded antigen but associated in a well containing only $200 \mu \mathrm{L}$ octet buffer was used as a baseline subtraction for data analysis.

Biolayer interferometry (Octet) Binding Experiments IgG competition. All reactions were run on an Octet Red 96 and samples were run in PBS with $0.1 \%$ BSA and $0.05 \%$ Tween 20 (octet buffer). IgGs produced from the scFvs from the above sort were assessed for their competition of binding with one another using anti-Penta HIS (His1K) biosensors (Sartorius/ForteBio). His1K tips 
were pre-quenched with buffer containing $10 \mathrm{nM}$ biotin. Tips were then loaded with 100nM protein for 2 mins (SARS-CoV-2 spike) or 4 mins (SARS-CoV-1 spike). These tips were then associated with one of seven antibodies (either CV27, COV2-2147, CV10, COVA2-14, COVA2-18, COV22449, COV2-2143) at $100 \mathrm{nM}$ for 5 mins to reach saturation. Tips were then baselined and associated with either 1 of the 7 antibodies. For this step all 8 tips went into the same antibody at 100nM. Response values (I.E. peak reached after 2 mins of association) was determined using the Octet data analysis software. Values were normalized to the tip loaded with either SARS-CoV2 or SARS-CoV-1 spike but without a competing antibody. These values were set as a value of 1 for each antibody. This is simply the antibody binding to the protein. Additionally, the antibody competing with itself was set to a value of zero. Final data analysis was done in Prism.

Biolayer interferometry (Octet) Binding Experiments - scFv-ACE2-Fusion. All reactions were run on an Octet Red 96 and samples were run in PBS with $0.1 \%$ BSA and $0.05 \%$ Tween 20. Streptavidin (SA) biosensors (Sartorius/ForteBio) were loaded for 2 mins with $100 \mathrm{nM}$ biotinylated antigens (SARS-CoV-2 or SARS-CoV-1 spike proteins). Samples were then washed and baselined in wells containing octet buffer. Association occurred in samples containing ACE2fusion proteins either without or with TEV protease (NEB) treatment. scFv-ACE2 fusions were tested at 200nM. Association was conducted for 2 min and dissociation was conducted for 1 min.

Biolayer interferometry (Octet) Binding Experiments - scFv-ACE2-fusion and CrossMAbACE2-fusion competition with hFC-ACE2. All reactions were run on an Octet Red 96 and samples were run in PBS with 0.1\% BSA and 0.05\% Tween 20 (octet buffer). Streptavidin (SA) biosensors (Sartorius/ForteBio) (scFvs) or HIS 1K biosensors (Sartorius/ForteBio) (CrossMAb) were loaded for 2 mins with $100 \mathrm{nM}$ biotinylated antigens (SARS-CoV-2 or SARS-CoV-1 spike - scFvs) or 4 mins with $200 \mathrm{nM}$ his-tagged antigens (CrossMAb). Samples were then washed and baselined in wells containing octet buffer. scFv-ACE2-fusions or CrossMAbs were then associated for 5 mins. Samples were baselined and then associated with either hFc-ACE2 for 2 mins (scFv) or 40 seconds (CrossMAb). Response values was determined using the Octet data analysis software. 
Samples which loaded SARS-CoV-2 or SARS-CoV-1 but did not associate with any hFc-ACE2 were used as a baseline subtraction. Values were normalized to the binding of hFc-ACE2 without a competitor.

\section{$\underline{\text { Lentivirus Production }}$}

SARS-CoV-2, VOCs, and SARS-CoV-1 spike pseudotyped lentiviral particles were produced. Viral transfections were done in HEK293T cells using calcium phosphate transfection reagent. Six million cells were seeded in D10 media (DMEM + additives: 10\% FBS, L-glutamate, penicillin, streptomycin, and $10 \mathrm{mM}$ HEPES) in $10 \mathrm{~cm}$ plates one day prior to transfection. A fiveplasmid system (plasmids described above) was used for viral production, as described in Crawford et al., 2020. The Spike vector contained the 21 amino acid truncated form of the SARSCoV-2 Spike sequence from the Wuhan-Hu-1 strain of SARS-CoV-2 or VOCs, or 18 amino acid truncation for SARS-CoV-1. VOCs were based off WT - Sequence ID: BCN86353.1, Alpha Sequence ID: QXN08428.1, Beta - Sequence ID: QUT64557.1, Gamma - Sequence ID: QTN71704.1, Delta - sequence ID: QWS06686.1 which also has V70F and A222V mutations, and Omicron - sequence ID: UFO69279.1. The plasmids were added to D10 medium in the following ratios: $10 \mu \mathrm{g}$ pHAGE-Luc2-IRS-ZsGreen, 3.4 $\mu \mathrm{g}$ FL Spike, $2.2 \mu \mathrm{g}$ HDM-Hgpm2, $2.2 \mu \mathrm{g}$ HDM-Tat1b, $2.2 \mu \mathrm{g}$ pRC-CMV-Rev1b in a final volume of $1000 \mu \mathrm{L}$. To form transfection complexes, $30 \mu \mathrm{L}$ BioT (BioLand) was added. Transfection reactions were incubated for $10 \mathrm{~min}$ at RT, and then $9 \mathrm{~mL}$ of medium was added slowly. The resultant $10 \mathrm{~mL}$ was added to plated HEK cells from which the medium had been removed. Culture medium was removed 24 hours posttransfection and replaced with fresh D10 medium. Viral supernatants were harvested 72 hours post-transfection by spinning at $300 \mathrm{x} \mathrm{g}$ for $5 \mathrm{~min}$ followed by filtering through a $0.45 \mu \mathrm{m}$ filter. Viral stocks were aliquoted and stored at $-80^{\circ} \mathrm{C}$ until further use.

\section{Neutralization}


The target cells used for infection in viral neutralization assays were from a HeLa cell line stably overexpressing the SARS-CoV-2 receptor, ACE2, as well as the protease known to process SARS-CoV-2, TMPRSS2. Production of this cell line is described in detail in Rogers et al., 2020, with the addition of stable TMPRSS2 incorporation. ACE2/TMPRSS2/HeLa cells were plated one day prior to infection at 5,000 cells per well. 96 well white walled, white bottom plates were used for the assay (Thermo Fisher Scientific). On the day of the assay, purified CrossMAbor scFv-ACE2 fusions in HEPES $(20 \mathrm{mM}), \mathrm{NaCl}(150 \mathrm{mM})$, which either had or had not been treated with TEV protease (as above), were sterile filtered using a $.22 \mu \mathrm{m}$ filter. Dilutions of this filtered stock were made into sterile 1xDPBS (Thermo Fisher Scientific) which was $5 \%$ by volume D10 medium. Each dilution well contained $30 \mu \mathrm{L}$ of CrossMAb- or scFv-ACE2 fusions. Samples were run in technical duplicate in each experiment. Virus only wells and cell only wells other wells contained only $30 \mu \mathrm{L}$ 1xDPBS.

A virus mixture was made containing the virus of interest (for example SARS-CoV-2), and D10 media (DMEM + additives: 10\% FBS, L-glutamate, penicillin, streptomycin, and $10 \mathrm{mM}$ HEPES). Virus dilutions into media were selected such that a suitable signal would be obtained in the virus only wells. A suitable signal was selected such that the virus only wells would achieve a luminescence of at least $>10,000 \mathrm{RLU} .90 \mu \mathrm{L}$ of this virus mixture was added to each of the inhibitor dilutions to make a final volume of $120 \mu \mathrm{L}$ in each well. Virus only wells were made which contained $30 \mu \mathrm{L} 1$ xDPBS and $90 \mu \mathrm{L}$ virus mixture. Cells only wells were made which contained $30 \mu \mathrm{L} 1 \mathrm{xDPBS}$ and $90 \mu \mathrm{L} \mathrm{D} 10$ media.

The inhibitor/virus mixture was left to incubate for 1 hour at $37^{\circ} \mathrm{C}$. Following incubation, the medium was removed from the cells on the plates made 1 day prior. This was replaced with $100 \mu \mathrm{L}$ of inhibitor/virus dilutions and incubated at $37^{\circ} \mathrm{C}$ for approximately 24 hours. At 24 hours post infection the media was exchanged for fresh media in all samples containing a TEV cleavable linker with our without cleavage, media was not exchanged on samples which did not have a TEV cleavable linker (for example WT IgGs). Infectivity readout was performed by measuring 
luciferase levels. 48 hours post infection $50 \mu \mathrm{L}$ of medium was removed from all cells were lysed by the addition of $50 \mu \mathrm{L}$ BriteLite $^{\mathrm{TM}}$ assay readout solution (Perkin Elmer) into each well, alternatively, all the media was removed and a 1:1 dilution of BriteLite ${ }^{\mathrm{TM}}$ was used. Luminescence values were measured using a BioTek Synergy ${ }^{\mathrm{TM}}$ HT Microplate Reader (BioTek) plate reader. Each plate was normalized by averaging cells only ( $0 \%$ infectivity) and virus only ( $100 \%$ infectivity) wells. Cells only and virus only wells were averaged. Normalized values were fit with a four parameter non-linear regression inhibitor curve in Prism to obtain IC50 values. The average $\mathrm{NT}_{50}$ of two independent experiments are shown.

\section{ELISA}

IgG ELISAs against hCoV strains were performed. Streptavidin solution $(5 \mu \mathrm{g} / \mathrm{mL})$ was plated in $50 \mu \mathrm{L}$ in each well on a MaxiSorp (Thermo Fisher Scientific) microtiter plate in $50 \mathrm{mM}$ sodium bicarbonate $\mathrm{pH} 8.75$. This was left to incubate for 1 hour at room temperature. These were washed $3 x$ with $300 \mu \mathrm{L}$ of ddH2O using an ELx 405 Bio-Tex plate washer and blocked with 150uL Chonblock (Chondrex) for at least 1 hour at room temperature. Biotinylated hCoV spike proteins were added to each well at a concentration of $1 \mu \mathrm{g} / \mathrm{mL}$ and left to incubate overnight at $4^{\circ} \mathrm{C}$. Plates were washed $3 x$ with $300 \mu \mathrm{L}$ of $1 \times$ PBST and serial dilution of monoclonal antibodies (described above) were added, starting at $1 \mu \mathrm{M}$ and undergoing 10-fold serial dilutions. These were left to incubate for 1 hour at room temperature and then washed $3 x$ with PBST. Goat antihuman HRP (Abcam ab7153) was added at a 1:5,000 dilution in PBST. This was left to incubate at room temperature for 1 hour and then washed 6x with PBST. Finally, the plate was developed using $50 \mu \mathrm{L}$ of 1-StepTM Turbo-TMB-ELISA Substrate Solution (ThermoFisher) per well and the plates were quenched with $50 \mu \mathrm{L}$ of $2 \mathrm{M} \mathrm{H}_{2} \mathrm{SO}_{4}$ to each well. Plates were read at $450 \mathrm{~nm}$ and normalized for path length using a BioTek Synergy ${ }^{\mathrm{TM}}$ HT Microplate Reader.

\section{Dot blot analysis of hCoV expression}


Expi293F culture supernatants from hCoV spike antigen expressions using MirA preps as above were harvested 2 days post-transfection via centrifugation at $7000 \mathrm{~g}$ for $15 \mathrm{~min}$. Supernatants were spotted on a nitrocellulose membrane The blot was dried for 15 min in a fume hood. Following drying, $10 \mathrm{~mL}$ of $1 \times$ PBST $+5 \%$ blotting grade blocker (Bio-Rad) were added for $10 \mathrm{~min}$. Two microliters of mouse anti-hexa His antibody (BioLegend) were added to the $10 \mathrm{~mL}$ sample and incubated for $1 \mathrm{~h}$ at room temperature. Blots were washed 16 times with $9 \mathrm{~mL}$ of PBST. Ten milliliters of $1 x$ PBST $+5 \%$ blotting grade blocker with $2 \mu \mathrm{L}$ anti-mouse IgG1 (Abcam) were added and incubated for $1 \mathrm{~h}$ at room temperature. Blots were washed 16 times with $9 \mathrm{~mL}$ of PBST, developed using Pierce ECL Western blotting substrate, and imaged using a GE Amersham imager 600. 


\section{References}

1. Touret, F., Baronti, C., Bouzidi, H. S. \& de Lamballerie, X. In vitro evaluation of therapeutic antibodies against a SARS-CoV-2 Omicron B.1.1.529 isolate. bioRxiv (2022). doi:10.1101/2022.01.01.474639

2. Kim, C. et al. A therapeutic neutralizing antibody targeting receptor binding domain of SARS-CoV-2 spike protein. Nat. Commun. 12, 1-10 (2021).

3. Dong, J. et al. Genetic and structural basis for SARS-CoV-2 variant neutralization by a two-antibody cocktail. Nat. Microbiol. 6, 1233-1244 (2021).

4. Zost, S. J. et al. Potently neutralizing and protective human antibodies against SARSCoV-2. Nature 584, 443-449 (2020).

5. Baum, A. et al. REGN-COV2 antibodies prevent and treat SARS-CoV-2 infection in rhesus macaques and hamsters. Science 370, 1110-1115 (2020).

6. Chen, P. et al. SARS-CoV-2 Neutralizing Antibody LY-CoV555 in Outpatients with Covid19. N. Engl. J. Med. 384, 229-237 (2021).

7. Jones, B. E. et al. The neutralizing antibody, LY-CoV555, protects against SARS-CoV-2 infection in nonhuman primates. Sci. Transl. Med. 13, 1-18 (2021).

8. Gottlieb, R. L. et al. Effect of bamlanivimab as monotherapy or in combination with etesevimab on viral load in patients with mild to moderate COVID-19: A randomized clinical trial. JAMA - J. Am. Med. Assoc. 325, 632-644 (2021).

9. Pinto, D. et al. Cross-neutralization of SARS-CoV-2 by a human monoclonal SARS-CoV antibody. Nature 583, 290-295 (2020).

10. Cameroni, E. et al. Broadly neutralizing antibodies overcome SARS-CoV-2 Omicron antigenic shift. Nature 2021.12.12.472269 (2021). doi:10.1038/d41586-021-03825-4

11. VanBlargan, L. A. et al. An infectious SARS-CoV-2 B.1.1.529 Omicron virus escapes 
neutralization by therapeutic monoclonal antibodies. Nat. Med. (2022).

doi:10.1038/s41591-021-01678-y

12. Greaney, A. J. et al. Comprehensive mapping of mutations in the SARS-CoV-2 receptorbinding domain that affect recognition by polyclonal human plasma antibodies. Cell Host Microbe 29, 463-476.e6 (2021).

13. Piccoli, L. et al. Mapping Neutralizing and Immunodominant Sites on the SARS-CoV-2 Spike Receptor-Binding Domain by Structure-Guided High-Resolution Serology. Cell 183, 1024-1042.e21 (2020).

14. Starr, T. N. et al. SARS-CoV-2 RBD antibodies that maximize breadth and resistance to escape. Nature 597, 97-102 (2021).

15. Greaney, A. J. et al. Mapping mutations to the SARS-CoV-2 RBD that escape binding by different classes of antibodies. Nat. Commun. 12, (2021).

16. Barnes, C. O. et al. SARS-CoV-2 neutralizing antibody structures inform therapeutic strategies. Nature 588, 682-687 (2020).

17. Hastie, K. et al. Defining variant-resistant epitopes targeted by SARS-CoV-2 antibodies: A global consortium study. Science 374, 472-478 (2021).

18. Weisblum, Y. et al. Escape from neutralizing antibodies by SARS-CoV-2 spike protein variants. Elife 9, e61312 (2020).

19. Lan, J. et al. Structure of the SARS-CoV-2 spike receptor-binding domain bound to the ACE2 receptor. Nature 581, 215-220 (2020).

20. Hoffmann, M. et al. SARS-CoV-2 Cell Entry Depends on ACE2 and TMPRSS2 and Is Blocked by a Clinically Proven Protease Inhibitor. Cell 181, 271-280.e8 (2020).

21. Hansen, J. et al. Studies in humanized mice and convalescent humans yield a SARSCoV-2 antibody cocktail. Science 369, 1010-1014 (2020).

22. Gupta, A. et al. Early Treatment for Covid-19 with SARS-CoV-2 Neutralizing Antibody Sotrovimab. N. Engl. J. Med. 385, 1941-1950 (2021). 
23. Gaudinski, M. R. et al. Safety and pharmacokinetics of the Fc-modified HIV-1 human monoclonal antibody VRC01LS: A Phase 1 open-label clinical trial in healthy adults. PLoS Med. 15, e1002493-e1002493 (2018).

24. Ko, S.-Y. et al. Enhanced neonatal Fc receptor function improves protection against primate SHIV infection. Nature 514, 642-645 (2014).

25. Zalevsky, J. et al. Enhanced antibody half-life improves in vivo activity. Nat. Biotechnol. 28, 157-159 (2010).

26. Walls, A. C. et al. Structure, Function, and Antigenicity of the SARS-CoV-2 Spike Glycoprotein. Cell 181, 281-292.e6 (2020).

27. Celniker, G. et al. ConSurf: Using evolutionary data to raise testable hypotheses about protein function. Isr. J. Chem. 53, 199-206 (2013).

28. Ashkenazy, H. et al. ConSurf 2016: an improved methodology to estimate and visualize evolutionary conservation in macromolecules. Nucleic Acids Res. 44, W344-W350 (2016).

29. Ashkenazy, H., Erez, E., Martz, E., Pupko, T. \& Ben-Tal, N. ConSurf 2010: Calculating evolutionary conservation in sequence and structure of proteins and nucleic acids. Nucleic Acids Res. 38, 529-533 (2010).

30. Sievers, F. et al. Fast, scalable generation of high-quality protein multiple sequence alignments using Clustal Omega. Mol. Syst. Biol. 7, 539 (2011).

31. Edgar, R. C. MUSCLE: multiple sequence alignment with high accuracy and high throughput. Nucleic Acids Res. 32, 1792-1797 (2004).

32. Shang, J. et al. Cell entry mechanisms of SARS-CoV-2. Proc. Natl. Acad. Sci. U. S. A. 117, (2020).

33. Harvey, W. T. et al. SARS-CoV-2 variants, spike mutations and immune escape. Nat. Rev. Microbiol. 19, 409-424 (2021).

34. Garcia-Beltran, W. F. et al. mRNA-based COVID-19 vaccine boosters induce neutralizing 
immunity against SARS-CoV-2 Omicron variant. medRxiv Prepr. Serv. Heal. Sci. 1-10 (2021). doi:10.1101/2021.12.14.21267755

35. Schmidt, F. et al. High genetic barrier to SARS-CoV-2 polyclonal neutralizing antibody escape. Nature 600, 512-516 (2021).

36. Okuno, Y., Isegawa, Y., Sasao, F. \& Ueda, S. A common neutralizing epitope conserved between the hemagglutinins of influenza A virus $\mathrm{H} 1$ and $\mathrm{H} 2$ strains. J. Virol. 67, 2552-8 (1993).

37. Ekiert, D. C. \& Wilson, I. A. Broadly neutralizing antibodies against influenza virus and prospects for universal therapies. Curr. Opin. Virol. 2, 134-141 (2012).

38. Burton, D. R., Poignard, P., Stanfield, R. L. \& Wilson, I. A. Broadly neutralizing antibodies present new prospects to counter highly antigenically diverse viruses. Science $337,183-$ 186 (2012).

39. Lanzavecchia, A., Frühwirth, A., Perez, L. \& Corti, D. Antibody-guided vaccine design: Identification of protective epitopes. Curr. Opin. Immunol. 41, 62-67 (2016).

40. Pica, N. \& Palese, P. Toward a Universal Influenza Virus Vaccine: Prospects and Challenges. Annu. Rev. Med. 64, 189-202 (2013).

41. Weidenbacher, P. A. P. A. \& Kim, P. S. P. S. P. S. Protect, modify, deprotect (PMD): A strategy for creating vaccines to elicit antibodies targeting a specific epitope. Proc. Natl. Acad. Sci. 116, 9947 LP - 9952 (2019).

42. Li, W. et al. Structural Basis and Mode of Action for Two Broadly Neutralizing Antibodies Against SARS-CoV-2 Emerging Variants of Concern. Cell Rep. 110210 (2021). doi:10.1016/j.celrep.2021.110210

43. Sauer, M. M. et al. Structural basis for broad coronavirus neutralization. Nat. Struct. Mol. Biol. 28, 478-486 (2021).

44. Pinto, D. et al. Broad betacoronavirus neutralization by a stem helix-specific human antibody. Science 373, 1109-1116 (2021). 
45. Zhou, P. et al. A protective broadly cross-reactive human antibody defines a conserved site of vulnerability on beta-coronavirus spikes. bioRxiv Prepr. Serv. Biol. 1-38 (2021). doi:10.1101/2021.03.30.437769

46. Xiangyang, C. et al. A neutralizing human antibody binds to the N-terminal domain of the Spike protein of SARS-CoV-2. Science 369, 650-655 (2020).

47. McCallum, M. et al. N-terminal domain antigenic mapping reveals a site of vulnerability for SARS-CoV-2. Cell 184, 2332-2347.e16 (2021).

48. Liu, L. et al. Potent neutralizing antibodies against multiple epitopes on SARS-CoV-2 spike. Nature 584, 450-456 (2020).

49. Amanat, F. et al. The plasmablast response to SARS-CoV-2 mRNA vaccination is dominated by non-neutralizing antibodies that target both the NTD and the RBD. medRxiv Prepr. Serv. Heal. Sci. (2021). doi:10.1101/2021.03.07.21253098

50. Aydillo, T. et al. Immunological imprinting of the antibody response in COVID-19 patients. Nat. Commun. 12, 1-13 (2021).

51. Seydoux, E. et al. Characterization of neutralizing antibodies from a SARS-CoV-2 infected individual. bioRxiv Prepr. Serv. Biol. 2020.05.12.091298 (2020). doi:10.1101/2020.05.12.091298

52. Wheatley, A. K. et al. Immune imprinting and SARS-CoV-2 vaccine design. Trends Immunol. 42, 956-959 (2021).

53. Huang, K. Y. A. et al. Breadth and function of antibody response to acute SARS-CoV-2 infection in humans. PLoS Pathog. 17, 1-26 (2021).

54. Z., W. A. et al. Broad neutralization of SARS-related viruses by human monoclonal antibodies. Science 369, 731-736 (2020).

55. Jencks, W. P. On the attribution and additivity of binding energies. Proc. Natl. Acad. Sci. 78, 4046 LP - 4050 (1981).

56. Lim, S. A. et al. Bispecific VH/Fab antibodies targeting neutralizing and non-neutralizing 
Spike epitopes demonstrate enhanced potency against SARS-CoV-2. MAbs 13, 1-10 (2021).

57. Raybould, M. I. J., Kovaltsuk, A., Marks, C. \& Deane, C. M. CoV-AbDab: The coronavirus antibody database. Bioinformatics 37, 734-735 (2021).

58. Seydoux, E. et al. Analysis of a SARS-CoV-2-Infected Individual Reveals Development of Potent Neutralizing Antibodies with Limited Somatic Mutation. Immunity 53, 98-105.e5 (2020).

59. Zost, S. J. et al. Rapid isolation and profiling of a diverse panel of human monoclonal antibodies targeting the SARS-CoV-2 spike protein. Nat. Med. 26, 1422-1427 (2020).

60. Brouwer, P. J. M. et al. Potent neutralizing antibodies from COVID-19 patients define multiple targets of vulnerability. Science 369, 643-650 (2020).

61. Ackerman, M. et al. Highly avid magnetic bead capture: An efficient selection method for de novo protein engineering utilizing yeast surface display. Biotechnol. Prog. 25, 774783 (2009).

62. Gai, S. A. \& Wittrup, K. D. Yeast surface display for protein engineering and characterization. Curr. Opin. Struct. Biol. 17, 467-473 (2007).

63. Boder, E. T. \& Wittrup, K. D. Yeast surface display for screening combinatorial polypeptide libraries. Nat. Biotechnol. 15, 553-557 (1997).

64. Herzenberg, L. A., Sweet, R. G. \& Herzenberg, L. A. Fluorescence-activated cell sorting. Sci. Am. 234, 108-117 (1976).

65. Lui, I. et al. Trimeric SARS-CoV-2 Spike interacts with dimeric ACE2 with limited intraSpike avidity. bioRxiv (2020). doi:10.1101/2020.05.21.109157

66. Tan, C. W. et al. A SARS-CoV-2 surrogate virus neutralization test based on antibodymediated blockage of ACE2-spike protein-protein interaction. Nat. Biotechnol. 38, 10731078 (2020).

67. Schaefer, W. et al. Immunoglobulin domain crossover as a generic approach for the 
production of bispecific IgG antibodies. Proc. Natl. Acad. Sci. U. S. A. 108, 11187-11192 (2011).

68. Klein, C. et al. Engineering therapeutic bispecific antibodies using CrossMab technology. Methods 154, 21-31 (2019).

69. Klein, C., Schaefer, W. \& Regula, J. T. The use of CrossMAb technology for the generation of bi- and multispecific antibodies. MAbs 8, 1010-1020 (2016).

70. Lei, C. et al. Neutralization of SARS-CoV-2 spike pseudotyped virus by recombinant ACE2-lg. Nat. Commun. 11, 1-5 (2020).

71. Leach, A. et al. A tetrameric ACE2 protein broadly neutralizes SARS-CoV-2 spike variants of concern with elevated potency. Antiviral Res. 194, 105147 (2021).

72. Glasgow, A. et al. Engineered ACE2 receptor traps potently neutralize SARS-CoV-2. Proc. Natl. Acad. Sci. U. S. A. 117, 28046-28055 (2020).

73. Chan, K. K., Tan, T. J. C., Narayanan, K. K. \& Procko, E. An engineered decoy receptor for SARS-CoV-2 broadly binds protein S sequence variants. Sci. Adv. 7, 1-10 (2021).

74. Higuchi, Y. et al. High affinity modified ACE2 receptors prevent SARS-CoV-2 infection. bioRxiv 2020.09.16.299891 (2020).

75. Song, Y. et al. Discovery of Aptamers Targeting the Receptor-Binding Domain of the SARS-CoV-2 Spike Glycoprotein. Anal. Chem. 92, 9895-9900 (2020).

76. Valero, J. et al. A serum-stable RNA aptamer specific for SARS-CoV-2 neutralizes viral entry. Proc. Natl. Acad. Sci. 118, e2112942118 (2021).

77. Bell, B. N., Powell, A. E., Rodriguez, C., Cochran, J. R. \& Kim, P. S. Neutralizing antibodies targeting the SARS-CoV-2 receptor binding domain isolated from a naïve human antibody library. Protein Sci. 30, 716-727 (2021).

78. Raj, V. S. et al. Dipeptidyl peptidase 4 is a functional receptor for the emerging human coronavirus-EMC. Nature 495, 251-254 (2013).

79. N., S. T. et al. Prospective mapping of viral mutations that escape antibodies used to 
bioRxiv preprint doi: https://doi.org/10.1101/2022.01.24.477625; this version posted January 25, 2022. The copyright holder for this preprint (which was not certified by peer review) is the author/funder, who has granted bioRxiv a license to display the preprint in perpetuity. It is made available under aCC-BY-NC-ND 4.0 International license.

treat COVID-19. Science 371, 850-854 (2021).

80. Dunand, C. J. H. et al. Both Neutralizing and Non-neutralizing Human H7N9 Influenza Vaccine-induced Monoclonal Antibodies Confer Protection. Cell Host Microbe 19, 800813 (2016). 


\section{Supplementary Information}

\section{Sequences:}

\section{Signal Peptide}

Hexa-His tag

TEV Site

$\underline{\text { ACE2 }}$

CV10-ACE2 Fusion scFv

MGWSCILFLVATATGVHSQVQLQESGPGLVKPSETLSLTCNVSGGSISSYYWSWIRQP PGKGLEWIGYIYYSGSTNYNPSLKSRVTISVDTSKNQFSLKLSSVTAADTAVYYCARGFD YWGQGTLVTVSSASGGGGSGGGGSGGGGSEIVLTQSPGTLSLSPGERATLSCRASQSVS SIYLAWYQQKPGQAPRLLIYGASSRATGIPDRFSGSGSGTDFTLTISRLEPEDFAVYYCQQ YAGSPWTFGQGTKVEIKGGSGS $\underline{H H H H H H A S T G G G S G G P S G Q A G A A A S E E N L Y F Q G S L F ~}$ VSNHAYGGSGGEARVSTIEEQAKTFLDKFNHEAEDLFYQSSLASWNYNTNITEENVQN MNNAGDKWSAFLKEQSTLAQMYPLQEIQNLTVKLQLQALQQNGSSVLSEDKSKRLNTI LNTMSTIYSTGKVCNPDNPQECLLLEPGLNEIMANSLDYNERLWAWESWRSEVGKQLR PLYEEYVVLKNEMARANHYEDYGDYWRGDYEVNGVDGYDYSRGQLIEDVEHTFEEIK PLYEHLHAYVRAKLMNAYPSYISPIGCLPAHLLGDMWGRFWTNLYSLTVPFGQKPNID VTDAMVDQAWDAQRIFKEAEKFFVSVGLPNMTQGFWENSMLTDPGNVQKAVCHPTA 
WDLGKGDFRILMCTKVTMDDFLTAHHEMGHIQYDMAYAAQPFLLRNGANEGFHEAV GEIMSLSAATPKHLKSIGLLSPDFQEDNETEINFLLKQALTIVGTLPFTYMLEKWRWMVF KGEIPKDQWMKKWWEMKREIVGVVEPVPHDETYCDPASLFHVSNDYSFIRYYTRTLYQ FQFQEALCQAAKHEGPLHKCDISNSTEAGQKLFNMLRLGKSEPWTLALENVVGAKNMN VRPLLNYFEPLFTWLKDQNKNSFVGWSTDWSPYAD

\section{CV27-ACE2 Fusion scFv}

MGWSCILFLVATATGVHSQVQLVESGGGVVQPGRSLRLSCAASGFTFSSYAMHWVR QAPGKGLEWVALISYDGSNKYYADSVKGRFTISRDNSKNTLYLQMNSLRAEDTAVYYC ARSFGGSYYYGMDVWGQGTTVTASGGGGSGGGGSGGGGSQSALTQPASVSGSPGQSIT ISCTGTSSDVGGYNYVSWYQQHPGKAPKLMIYDVSNRPSGVSNRFSGSKSGNTASLTIS GLQAEDEADYYCSSYTSSSTPYVFGTGTKVGGSGS $\underline{H H H H H A S T G G G S G G P S G Q A G A A ~}$ ASEENLYFQGSLFVSNHAYGGSGGEARVSTIEEQAKTFLDKFNHEAEDLFYQSSLASWN YNTNITEENVQNMNNAGDKWSAFLKEQSTLAQMYPLQEIQNLTVKLQLQALQQNGSSV LSEDKSKRLNTILNTMSTIYSTGKVCNPDNPQECLLLEPGLNEIMANSLDYNERLWAWE SWRSEVGKQLRPLYEEYVVLKNEMARANHYEDYGDYWRGDYEVNGVDGYDYSRGQL IEDVEHTFEEIKPLYEHLHAYVRAKLMNAYPSYISPIGCLPAHLLGDMWGRFWTNLYSL TVPFGQKPNIDVTDAMVDQAWDAQRIFKEAEKFFVSVGLPNMTQGFWENSMLTDPGN VQKAVCHPTAWDLGKGDFRILMCTKVTMDDFLTAHHEMGHIQYDMAYAAQPFLLRN GANEGFHEAVGEIMSLSAATPKHLKSIGLLSPDFQEDNETEINFLLKQALTIVGTLPFTYM LEKWRWMVFKGEIPKDQWMKKWWEMKREIVGVVEPVPHDETYCDPASLFHVSNDYS 
FIRYYTRTLYQFQFQEALCQAAKHEGPLHKCDISNSTEAGQKLFNMLRLGKSEPWTLAL ENVVGAKNMNVRPLLNYFEPLFTWLKDQNKNSFVGWSTDWSPYAD

\section{COVA2-14-ACE2 Fusion scFv}

MGWSCILFLVATATGVHSQVQLVQSGAEVKKPGSSVKVSCKASGGTFSSYAIIWVRQ APGQGLEWMGGIIPIFGTANYAQKFQGRVTITTDESTSTAYMELSSLRSEDTAVYYCAR VRYYDSSGYYEDYWGQGTLVTVSSASGGGGSGGGGSGGGGSEIVLTQSPATLSLSPGER ATLSCRASQSVSSYLAWYQQEPGQAPRLLIYDASNRATGIPARFSGSGSGTDFTLTISSLE PEDFAVYYCQQRSNWPPMYTFGQGTKVEIKGGSGS $\underline{H H H H H A S T G G G S G G P S G Q A G A ~}$ AASEENLYFQGSLFVSNHAYGGSGGEARVSTIEEQAKTFLDKFNHEAEDLFYQSSLASW NYNTNITEENVQNMNNAGDKWSAFLKEQSTLAQMYPLQEIQNLTVKLQLQALQQNGSS VLSEDKSKRLNTILNTMSTIYSTGKVCNPDNPQECLLLEPGLNEIMANSLDYNERLWAW ESWRSEVGKQLRPLYEEYVVLKNEMARANHYEDYGDYWRGDYEVNGVDGYDYSRGQ LIEDVEHTFEEIKPLYEHLHAYVRAKLMNAYPSYISPIGCLPAHLLGDMWGRFWTNLYS LTVPFGQKPNIDVTDAMVDQAWDAQRIFKEAEKFFVSVGLPNMTQGFWENSMLTDPG NVQKAVCHPTAWDLGKGDFRILMCTKVTMDDFLTAHHEMGHIQYDMAYAAQPFLLR NGANEGFHEAVGEIMSLSAATPKHLKSIGLLSPDFQEDNETEINFLLKQALTIVGTLPFTY MLEKWRWMVFKGEIPKDQWMKKWWEMKREIVGVVEPVPHDETYCDPASLFHVSNDY SFIRYYTRTLYQFQFQEALCQAAKHEGPLHKCDISNSTEAGQKLFNMLRLGKSEPWTLA LENVVGAKNMNVRPLLNYFEPLFTWLKDQNKNSFVGWSTDWSPYAD 
COV2-2449-ACE2 Fusion scFv

MGWSCIILFLVATATGVHSQVQLVESGGGVVQPGRSLRLSCATSGFTFSSFALHWVRQ APGKGLEWVTVISDDGNNKYYVDSVKGRFTISRDNSKNTLFLQMNSLRVEDTAIYYCA RASYNSNWSIGEYFRDWGQGTLVTVSSASGGGGSGGGGSGGGGSDIVMTQSPDSLAVS LGERATINCKSSQSLLYTSNNKNYLAWYQQKPGQPPKLLIYWASTRESGVPDRFSGSGS GTDFTLTISSLQAEDVAVYYCQQYYSPPWTFGQGTKVEIKGGSGS $\underline{H H H H H} H A S T G G G S$ GGPSGQAGAAASEENLYFQGSLFVSNHAYGGSGGEARVSTIEEQAKTFLDKFNHEAED LFYQSSLASWNYNTNITEENVQNMNNAGDKWSAFLKEQSTLAQMYPLQEIQNLTVKLQ LQALQQNGSSVLSEDKSKRLNTILNTMSTIYSTGKVCNPDNPQECLLLEPGLNEIMANSL DYNERLWAWESWRSEVGKQLRPLYEEYVVLKNEMARANHYEDYGDYWRGDYEVNG VDGYDYSRGQLIEDVEHTFEEIKPLYEHLHAYVRAKLMNAYPSYISPIGCLPAHLLGDM WGRFWTNLYSLTVPFGQKPNIDVTDAMVDQAWDAQRIFKEAEKFFVSVGLPNMTQGF WENSMLTDPGNVQKAVCHPTAWDLGKGDFRILMCTKVTMDDFLTAHHEMGHIQYDM AYAAQPFLLRNGANEGFHEAVGEIMSLSAATPKHLKSIGLLSPDFQEDNETEINFLLKQA LTIVGTLPFTYMLEKWRWMVFKGEIPKDQWMKKWWEMKREIVGVVEPVPHDETYCDP ASLFHVSNDYSFIRYYTRTLYQFQFQEALCQAAKHEGPLHKCDISNSTEAGQKLFNMLR LGKSEPWTLALENVVGAKNMNVRPLLNYFEPLFTWLKDQNKNSFVGWSTDWSPYAD

\section{COV2-2143-ACE2 Fusion scFv}


MGWSCIILFLVATATGVHSEVQLVESGGGLVQPGGSLRLSCAASGFTVSSNYMSWVR QAPGKGLEWVSVIYSAGSTYYADSVKGRFSISRDKSKNTLYLQMNSLRAEDTAVYYCA KEGGSGSLRYYYYGMDVWGQGTTVTVSSASGGGGSGGGGSGGGGSQSVVTQPPSASG TPGQRVTISCSGSSSNIGYNIVNWYQQLPGTAPKLLIYSNNQRPSGVPDRFSGSKSGTSAS LSISGLQSEDEADYYCAAWDDSLNGYVFGTGTKVTVLGGSGS $\underline{H H H H H A S T G G G S G G P}$ SGQAGAAASEENLYFQGSLFVSNHAYGGSGGEARVSTIEEQAKTFLDKFNHEAEDLFY QSSLASWNYNTNITEENVQNMNNAGDKWSAFLKEQSTLAQMYPLQEIQNLTVKLQLQ ALQQNGSSVLSEDKSKRLNTILNTMSTIYSTGKVCNPDNPQECLLLEPGLNEIMANSLDY NERLWAWESWRSEVGKQLRPLYEEYVVLKNEMARANHYEDYGDYWRGDYEVNGVD GYDYSRGQLIEDVEHTFEEIKPLYEHLHAYVRAKLMNAYPSYISPIGCLPAHLLGDMWG RFWTNLYSLTVPFGQKPNIDVTDAMVDQAWDAQRIFKEAEKFFVSVGLPNMTQGFWE NSMLTDPGNVQKAVCHPTAWDLGKGDFRILMCTKVTMDDFLTAHHEMGHIQYDMAY AAQPFLLRNGANEGFHEAVGEIMSLSAATPKHLKSIGLLSPDFQEDNETEINFLLKQALTI VGTLPFTYMLEKWRWMVFKGEIPKDQWMKKWWEMKREIVGVVEPVPHDETYCDPAS LFHVSNDYSFIRYYTRTLYQFQFQEALCQAAKHEGPLHKCDISNSTEAGQKLFNMLRLG KSEPWTLALENVVGAKNMNVRPLLNYFEPLFTWLKDQNKNSFVGWSTDWSPYAD

\section{$\underline{\text { Signal Peptide }}$}

Hexa-His tag

TEV Site

$\underline{\mathrm{ACE} 2}$

COV2-2449-LC-ACE2 Fusion 
MGWSCIILFLVATATGVHSDIVMTQSPDSLAVSLGERATINCKSSQSLLYTSNNKNYLA WYQQKPGQPPKLLIYWASTRESGVPDRFSGSGSGTDFTLTISSLQAEDVAVYYCQQYYS PPWTFGQGTKVEIKRTVAAPSVFIFPPSDEQLKSGTASVVCLLNNFYPREAKVQWKVDN ALQSGNSQESVTEQDSKDSTYSLSSTLTLSKADYEKHKVYACEVTHQGLSSPVTKSFNR GECGGSGS $\underline{H H H H H A S T G G G S G G P S G Q A G A A A S E E N L Y F Q G S L F V S N H A Y G G S G G E A ~}$ RVSTIEEQAKTFLDKFNHEAEDLFYQSSLASWNYNTNITEENVQNMNNAGDKWSAFLK EQSTLAQMYPLQEIQNLTVKLQLQALQQNGSSVLSEDKSKRLNTILNTMSTIYSTGKVC NPDNPQECLLLEPGLNEIMANSLDYNERLWAWESWRSEVGKQLRPLYEEYVVLKNEM ARANHYEDYGDYWRGDYEVNGVDGYDYSRGQLIEDVEHTFEEIKPLYEHLHAYVRAK LMNAYPSYISPIGCLPAHLLGDMWGRFWTNLYSLTVPFGQKPNIDVTDAMVDQAWDA QRIFKEAEKFFVSVGLPNMTQGFWENSMLTDPGNVQKAVCHPTAWDLGKGDFRILMCT KVTMDDFLTAHHEMGHIQYDMAYAAQPFLLRNGANEGFHEAVGEIMSLSAATPKHLK SIGLLSPDFQEDNETEINFLLKQALTIVGTLPFTYMLEKWRWMVFKGEIPKDQWMKKW WEMKREIVGVVEPVPHDETYCDPASLFHVSNDYSFIRYYTRTLYQFQFQEALCQAAKHE GPLHKCDISNSTEAGQKLFNMLRLGKSEPWTLALENVVGAKNMNVRPLLNYFEPLFTW LKDQNKNSFVGWSTDWSPYAD

\section{Signal Peptide}

\section{$\underline{\text { Knob/Hole Mutations }}$}

$\underline{\text { CrossMAb Swaps }}$ 
COV2-2449-HC-Knob

MGWSCIILFLVATATGVHSQVQLVESGGGVVQPGRSLRLSCATSGFTFSSFALHWVRQ APGKGLEWVTVISDDGNNKYYVDSVKGRFTISRDNSKNTLFLQMNSLRVEDTAIYYCA RASYNSNWSIGEYFRDWGQGTLVTVSSASTKGPSVFPLAPSSKSTSGGTAALGCLVKDY FPEPVTVSWNSGALTSGVHTFPAVLQSSGLYSLSSVVTVPSSSLGTQTYICNVNHKPSNT KVDKKVEPKSCDKTHTCPPCPAPELLGGPSVFLFPPKPKDTLMISRTPEVTCVVVDVSHE DPEVKFNWYVDGVEVHNAKTKPREEQYNSTYRVVSVLTVLHQDWLNGKEYKCKVSN KALPAPIEKTISKAKGQPREPQVYTLPPSRDELTKNQVSL $\underline{\boldsymbol{W} C L V K G F Y P S D I A V E W E S N G ~}$ QPENNYKTTPPVLDSDGSFFLYSKLTVDKSRWQQGNVFSCSVMHEALHNHYTQKSLSL SPGK

\section{CV10-LC-CrossMAb}

MGWSCIILFLVATATGVHSEIVLTQSPGTLSLSPGERATLSCRASQSVSSIYLAWYQQK PGQAPRLLIYGASSRATGIPDRFSGSGSGTDFTLTISRLEPEDFAVYYCQQYAGSPWTFGQ GTKVEIKSSASTKGPSVFPLAPSSKSTSGGTAALGCLVKDYFPEPVTVSWNSGALTSGVH TFPAVLQSSGLYSLSSVVTVPSSSLGTQTYICNVNHKPSNTKVDKKVEPKSC

\section{CV10-HC-CrossMAb-Hole}


MGWSCILFLVATATGVHSQVQLQESGPGLVKPSETLSLTCNVSGGSISSYYWSWIRQP

PGKGLEWIGYIYYSGSTNYNPSLKSRVTISVDTSKNQFSLKLSSVTAADTAVYYCARGFD

YWGQGTLVTVSSASVAAPSVFIFPPSDEQLKSGTASVVCLLNNFYPREAKVQWKVDNA

LQSGNSQESVTEQDSKDSTYSLSSTLTLSKADYEKHKVYACEVTHQGLSSPVTKSFNRG

ECDKTHTCPPCPAPELLGGPSVFLFPPKPKDTLMISRTPEVTCVVVDVSHEDPEVKFNWY

VDGVEVHNAKTKPREEQYNSTYRVVSVLTVLHQDWLNGKEYKCKVSNKALPAPIEKTI

SKAKGQPREPQVㄸTLPP $\underline{S} R D E L T K N Q V S L \underline{S} C A V K G F Y P S D I A V E W E S N G Q P E N N Y K T T P$

PVLDSDGSFFL $\underline{\boldsymbol{V} S K L T V D K S R W Q Q G N V F S C S V M H E A L H N H Y T Q K S L S L S P G K ~}$ 


\section{Figures:}

\section{Supplementary Fig. 1}

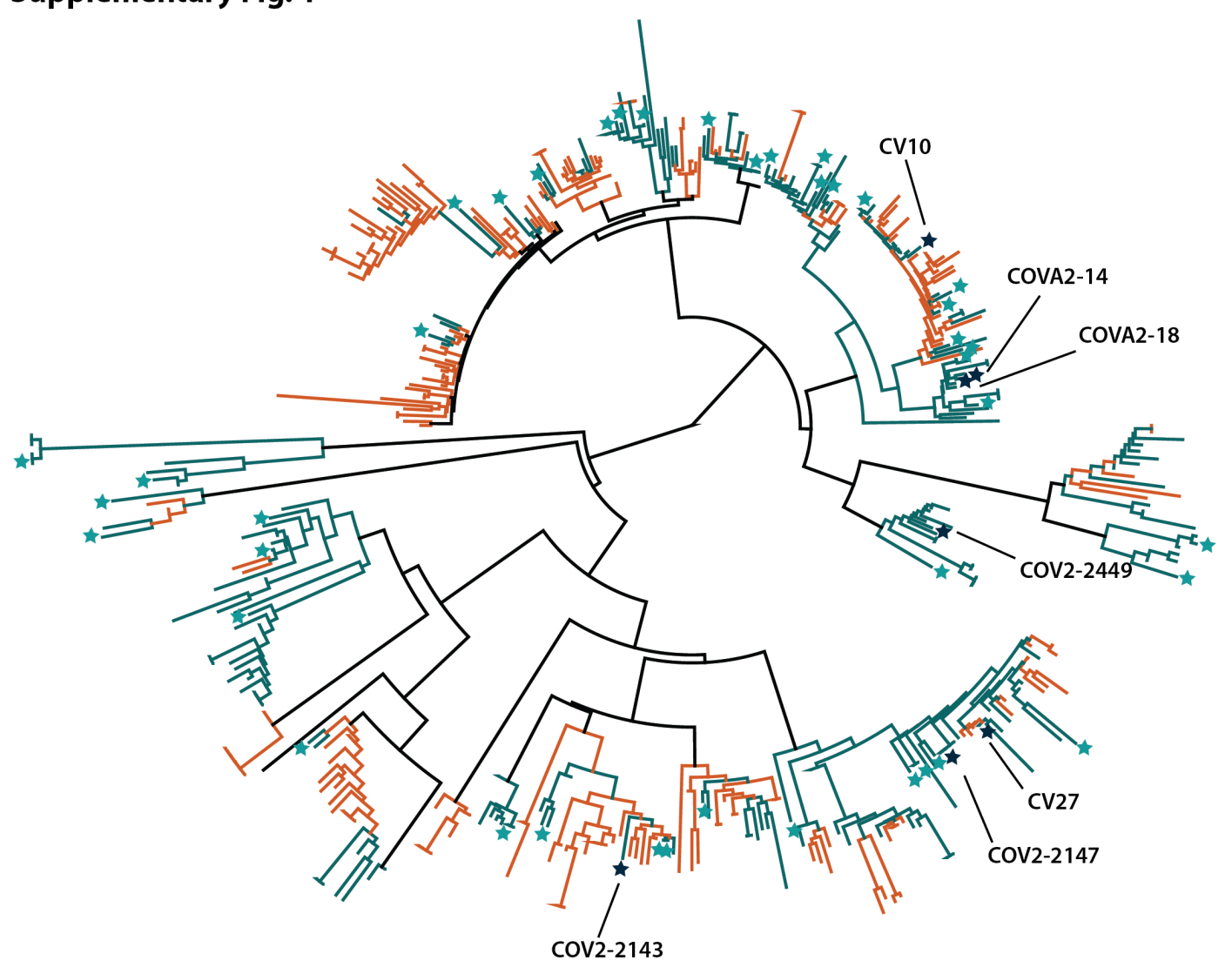

Supplementary Figure 1 - The non-RBD library was selected to prioritize diversity. A phylogenetic tree generated using Geneious Prime of 436 light chain sequences from a curated library of 696 anti-SARS-COV-2 spike antibody sequences. Labels same as Fig. 1. Germline alleles are not shown. Antibodies denoted with names were cross-reactive for SARS-CoV-1. 


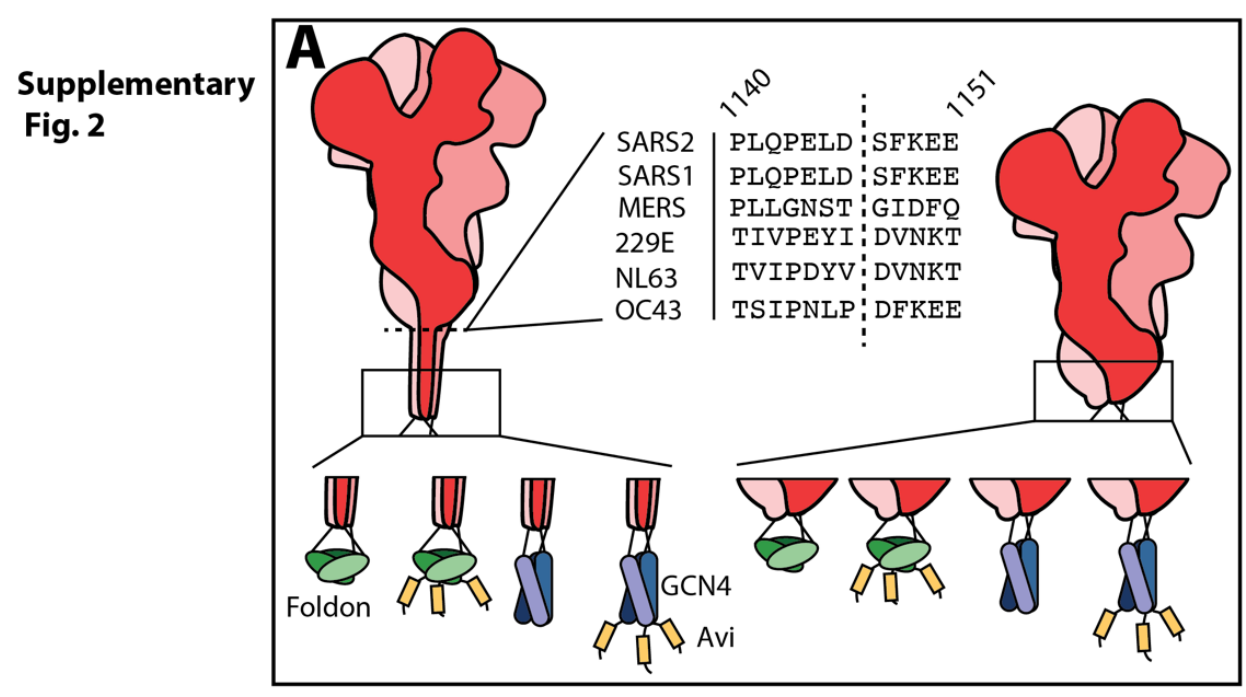
B
Thrombin
Foldon
His-Tag
Avi-Tag
LVPRGSPGS GYIPEAPRDGQAYVRKDGEWVLLSTFL-GHHHHHH G_GLNDIFEAQKIEWHE

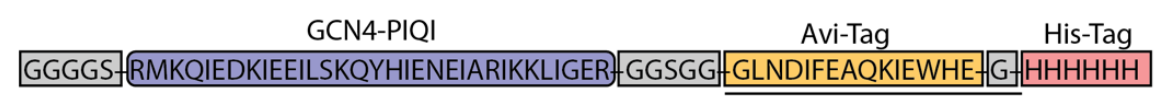
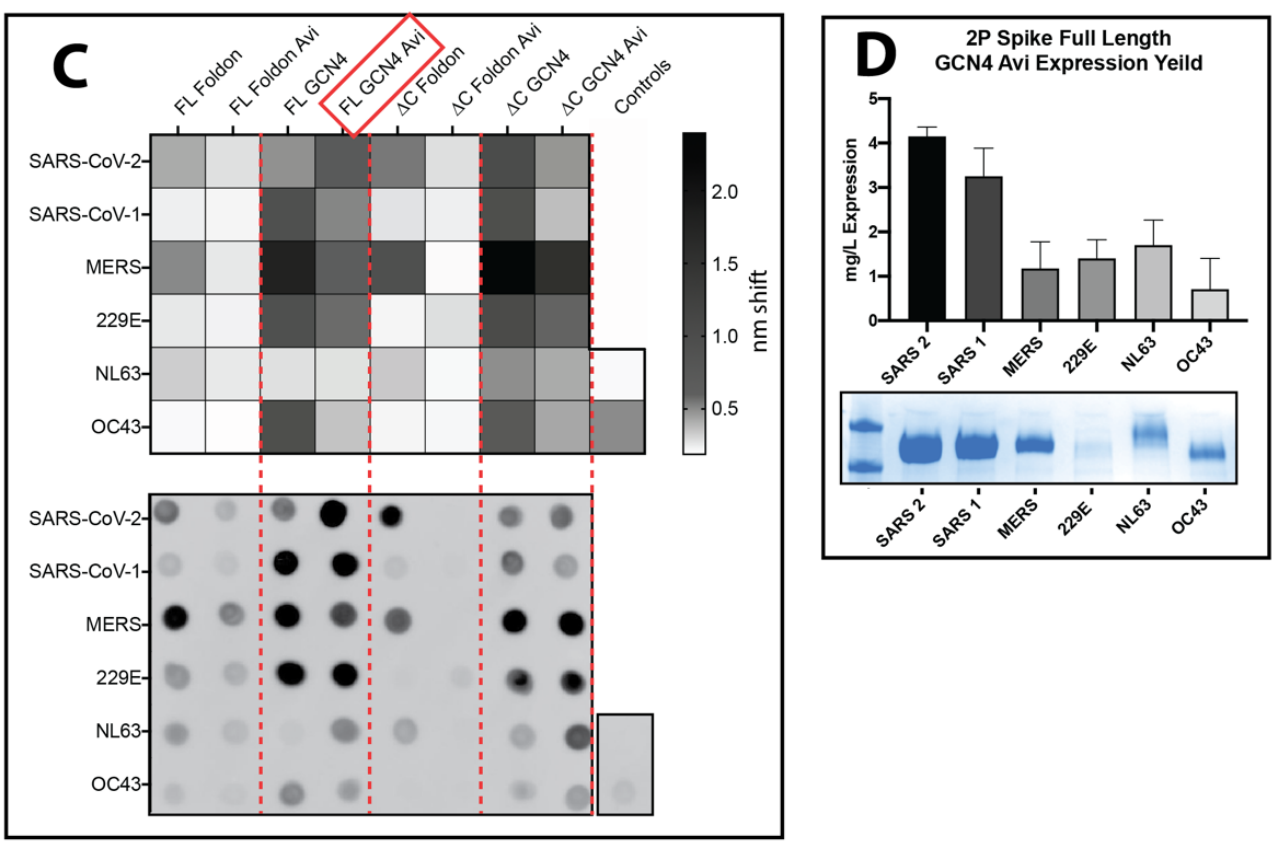

Supplementary Figure 2 - hCoV proteins expression is optimized with a GCN4 tag. (A) A schematic representation of constructs tested for expression. 6 hCoV spike proteins, either FL or truncated, tested with 4 different C-terminal trimerization domains and tags. $\Delta \mathrm{C}$ truncations shown in the middle, SARS-CoV-2 spike numbering. (B) linkers tested. For those without Avi tags, the underlined portions were removed. (C) (top) BLI binding responses from isolated Expi supernatants binding to His $1 \mathrm{~K}$ octet tips. Higher response corresponds to higher protein expression. (bottom) An anti-his tag dot blot assay of the supernatants tested in the BLI binding. Dot blot shows good correspondence with the BLI binding. Influenza hemagglutinin used as a positive control, mock transfection as a negative control. (D) Yield determined for full length 2P hCoV constructs containing the GCN4-Avi-His tag from a duplicate experiment of $100 \mathrm{~mL}$ transfections. 


\section{Supplementary Fig. 3}

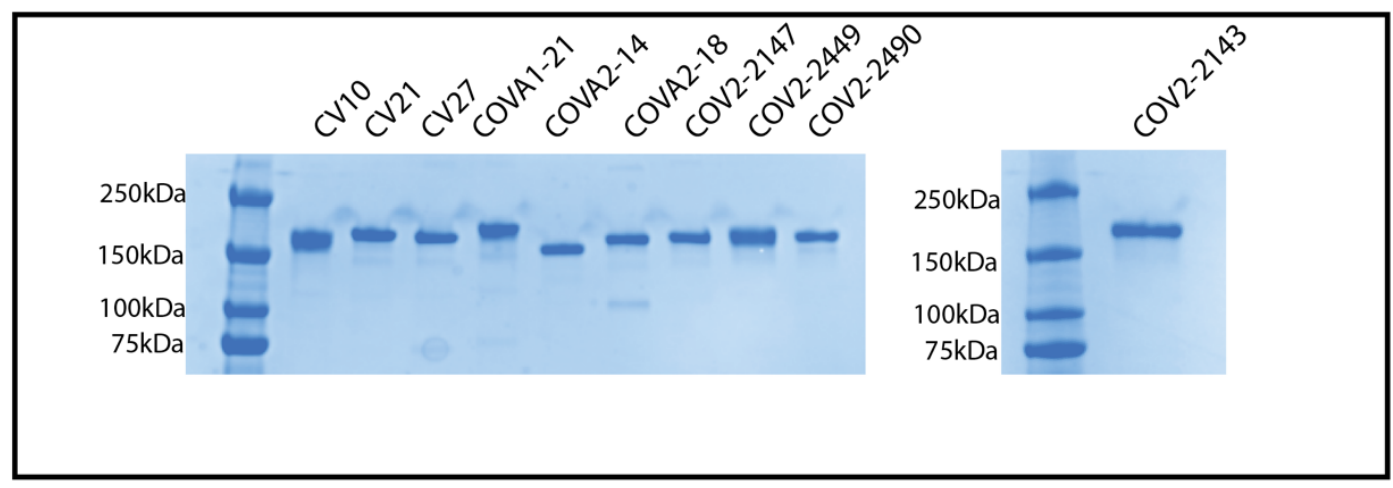

Supplementary Figure 3 - SDS-page analysis of of IgG proteins made from clones identified in the SARS-CoV-1 FACS sorts. MW ladders are in the left-most lanes of the two gels. 


\section{Supplementary Fig. 4}
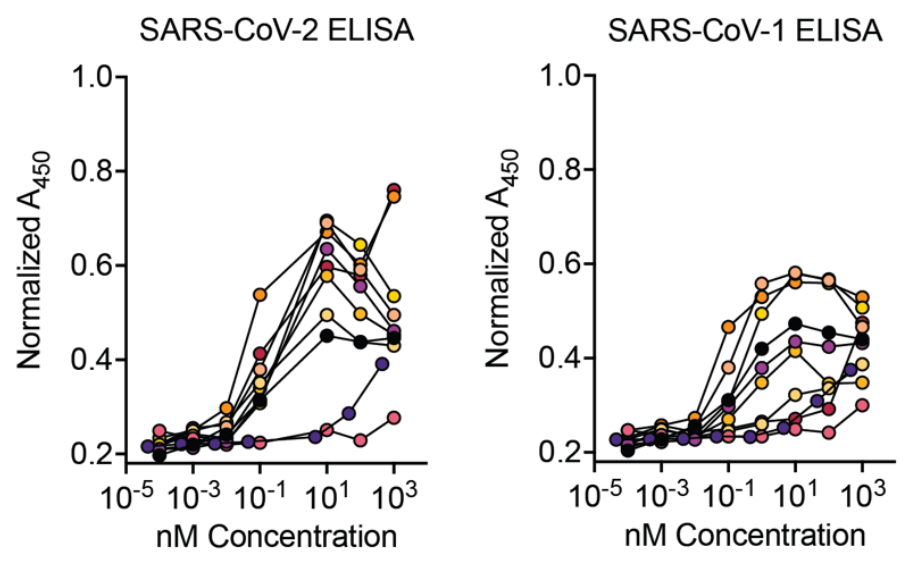

- CV10

- CV21

- CV27

- COVA1-21

- COVA2-14

- COVA2-18

o. COV2-2143

- COV2-2147

- COV2-2449

- cov2-2490

MERS ELISA
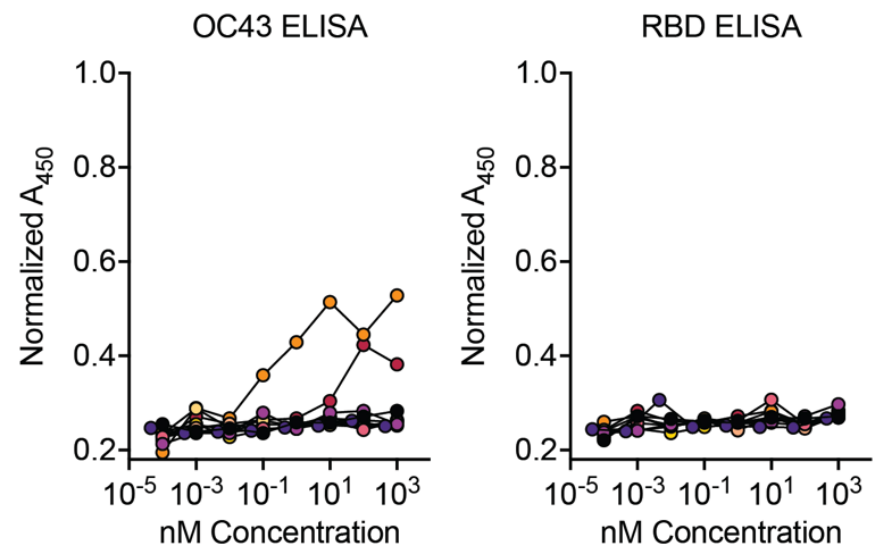

Supplementary Figure 4 - ELISA binding of IgG proteins made from ScFv clones identified by FACS sorting for SARS-CoV-1 binding. Biotinylated hCoV antigens were plated and dilutions of IgGs were tested for binding. Normalized $A_{450}$ calculated by adjusting for pathlength. Except for COV2-2490, CV21, COVA2-18 all IgGs bind to SARS-CoV-2 and SARS-CoV-1. 


\section{Supplementary Fig. 5}
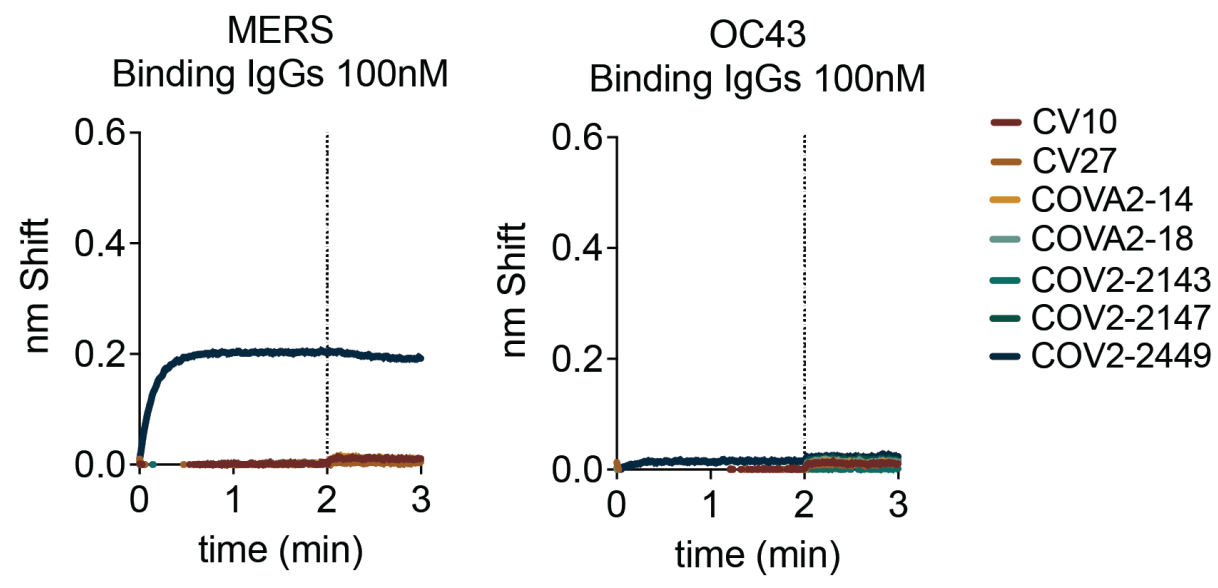

Supplementary Figure 5 - BLI binding for the 7 identified SARS-CoV-1 cross-reactive clones against MERS (left) or OC43 (right) spike proteins. Only COV2-2449 shows any binding affinity for MERS or weakly to OC43 spike proteins. 
bioRxiv preprint doi: https://doi.org/10.1101/2022.01.24.477625; this version posted January 25, 2022. The copyright holder for this preprint (which was not certified by peer review) is the author/funder, who has granted bioRxiv a license to display the preprint in perpetuity. It is made available under aCC-BY-NC-ND 4.0 International license.

\section{Supplementary Fig. 6}

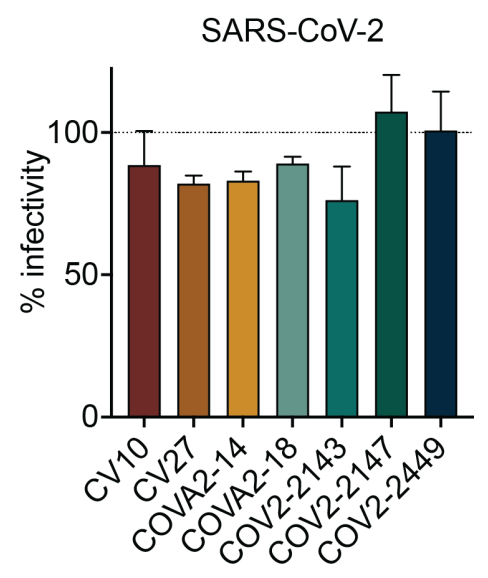

Supplementary Figure 6 - Single dilution (100 nM) neutralization against SARS-CoV-2 Wuhan-Hu-1 for the 7 identified cross-reactive antibodies. All antibodies show no neutralization at a high concentration of $100 \mathrm{nM}$. 
bioRxiv preprint doi: https://doi.org/10.1101/2022.01.24.477625; this version posted January 25, 2022. The copyright holder for this preprint (which was not certified by peer review) is the author/funder, who has granted bioRxiv a license to display the preprint in perpetuity. It is made available under aCC-BY-NC-ND 4.0 International license.

\title{
Supplementary Fig. 7
}

\author{
LC/SCFV-GGSGSHHHHHASTGGGSGGPSGQAGAAASEENLYFOGSLFVSNHAYGGSGGEARV-ACE2 \\ His Tag \\ TEV site
}

Supplementary Figure 7 - The linker used to tether ACE2 to either the C-terminus of the scFv or C-terminus of the COV2-2449 LC. The linker was designed to contain a Hexa-His tag for purification and a TEV site to facilitate proteolysis. 
bioRxiv preprint doi: https://doi.org/10.1101/2022.01.24.477625; this version posted January 25, 2022. The copyright holder for this preprint (which was not certified by peer review) is the author/funder, who has granted bioRxiv a license to display the preprint in perpetuity. It is made available under aCC-BY-NC-ND 4.0 International license.

\section{Supplementary Fig. 8}

\section{CV10-2449-XMAb \\ ACE2 competition}

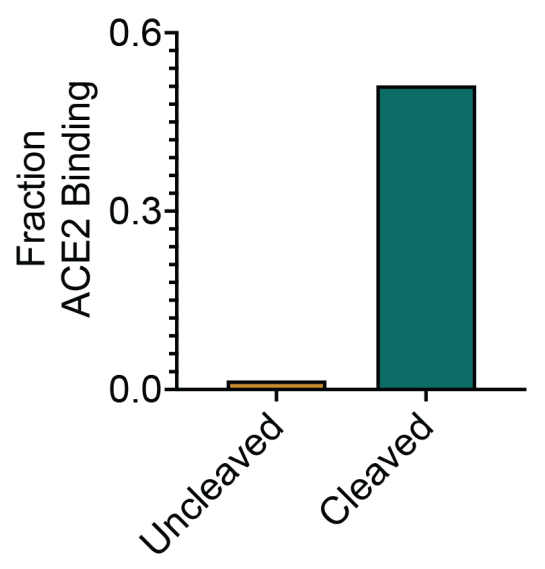

Supplementary Figure 8 - Relative hFc-ACE2 binding to SARS-CoV-2 spike protein which has been pre-associated with $200 \mathrm{nM}$ CV10-2449-XMAb (left) or the TEV cleaved form (right). No competitor was set to a value of 1.0. 